\title{
Durability of bonded FRP-to-steel joints: Effects of moisture, de-icing salt solution, temperature and FRP type
}

\author{
Mohsen Heshmati*, Reza Haghani, Mohammad Al-Emrani \\ Dept. of Civil and Environmental Engineering, Division of Structural Engineering, Chalmers University of Technology, Gothenburg, Sweden
}

\section{A R T I C L E I N F O}

\section{Article history:}

Received 24 November 2016

Received in revised form

17 January 2017

Accepted 19 March 2017

Available online 27 March 2017

\section{Keywords:}

Polymer-matrix composites (PMCs)

Environmental degradation

Mechanical properties

FRP-steel bonded joints

\begin{abstract}
A B S T R A C T
This paper investigates the effects of environmental ageing on the mechanical response of adhesively bonded double-lap shear joints made of steel and CFRP or GFRP adherents. One hundred and ninety-two specimens, 84 joints and 108 material coupons, were aged for up to three years in various environments including (i) immersion in distilled water at $20^{\circ} \mathrm{C}$ and $45^{\circ} \mathrm{C}$, (ii) immersion in de-icing salt solution at $20{ }^{\circ} \mathrm{C}$ and $45{ }^{\circ} \mathrm{C}$ and (iii) exposure to $95 \%$ relative humidity at $45{ }^{\circ} \mathrm{C}$. In general, immersion at $45{ }^{\circ} \mathrm{C}$ resulted in noticeably greater strength reductions at both material and joint level. While the strength and stiffness of the joints made of GFRP material underwent significant reductions, the CFRP/steel joints were affected to a considerably smaller degree. FE simulations showed the impact of the permeability of FRP adherents and moisture distribution at the FRP/adhesive interface on the integrity and strength of the joints. The joint-level results are compared with the most relevant durability data in the literature.
\end{abstract}

(c) 2017 Elsevier Ltd. All rights reserved.

\section{Introduction}

The design service life of many bridges is $80-120$ years. In spite of this, of the many bridges that were built in different parts of the world before the middle of the last century, the majority are still in service. In addition to ageing, severe deterioration caused by environmental exposure and/or increased traffic loads has led to an imminent need for the replacement, strengthening and retrofitting of a large stock of bridges, see, for example, [1]. The traditional methods for upgrading existing bridges involve the use of conventional building materials such as concrete, steel and timber in combination with mechanical joining techniques such as welding and bolting. These methods are, however, time and labour intensive and expensive. For this reason, cost-effective, durable upgrading techniques are of great interest to bridge owners.

One solution to this problem is to use new and advanced materials such as fibre-reinforced polymer (FRP) composites. FRP materials offer outstanding properties such as high specific strength and stiffness, electrochemical corrosion resistance and light weight. The advantages of FRPs in combination with adhesive bonding, as the preferred joining technique, include easy, rapid installation and cost efficiency. In the past four decades, the

\footnotetext{
* Corresponding author. Sven Hultins gata 8, SE-412 96 Gothenburg, Sweden.

E-mail address: mohsen.heshmati@chalmers.se (M. Heshmati).
}

application of bonded carbon fibre reinforced polymer (CFRP) materials has increasingly replaced the traditional methods of strengthening and repair for concrete structures [2]. In recent years, there has also been a great deal of interest in the repair of steel structures using bonded FRP materials mainly for corrosion damage [3]. Moreover, FRP materials have found their way into whole- and steel-FRP hybrid structures, using glass fibre reinforced polymer (GFRP) deck systems on steel girders, for example [4]. As a result, there is a great deal of interest in studying the behaviour of bonded $\mathrm{FRP} /$ steel joints from the short- and long-term perspective.

Even though the short-term behaviour and design of these joints has been studied extensively (see, for example, $[5,6]$ ), one important remaining gap is the lack of knowledge about the longterm performance and the durability of FRP/steel bonded joints used in bridge structures. Long-term exposure to harsh environmental conditions that can be possibly combined with cyclic or monotonic mechanical load cases are known to endanger the effectiveness and integrity of these joints. Few contributions are actually available in the literature about the cyclic behaviour of FRP joints, see, for example, $[7,8]$. Similarly, the available research on the subject of the durability and long-term performance is limited, which is due to the complex nature of research in this area that can be mainly attributed to time-consuming, complicated testing. At the present time, the lack of knowledge regarding the long-term performance of adhesive bonded joints is compensated for by applying a multiple combination of large safety factors to the 
strength of FRP materials, which dramatically increases material usage and reduces the design efficiency $[9,10]$.

A number of environmental parameters are known to affect the long-term characteristics of FRP/steel bonded joints, including moisture, thermal cycles and variations and UV radiation. A review of the literature reveals that the combination of temperature and moisture (which can take the form of humidity, liquid water or deicing salt solutions) can be the most severe condition when it comes to the durability of adhesive joints with FRP and metallic adherends [11-13]. The moisture penetrates into adhesively bonded joints through a diffusion process in the adhesive layer and/ or wicking along the interfaces between the adhesive and adherends and/or absorption through the porous adherends. This process is accelerated by increasing the exposure temperature [14]. Once moisture enters the joint, it affects the mechanical properties of the joint through two principal mechanisms; the degradation of the adhesive and/or adherends and the degradation of the adherend/ adhesive interface(s) [15]. Recently, some research has been conducted to obtain the moisture profile in bonded assemblies using advanced methods, such as electrochemical impedance spectroscopy (EIS) (see, for example, [16,17]). Nevertheless, one limitation of these methods is that they are not well established for joints with permeable adherends such as FRPs.

At bulk-material level, moisture can alter resins physically (reversible) through plasticisation and swelling and chemically (irreversible) through cracking and hydrolysis [11,18]. In addition, moisture ingress into FRP composites may lead to fibre/matrix debonding and the formation of micro-cracks [19-21]. For FRPs used in civil engineering applications, Karbhari [11] predicts a negligible modulus change of the order of $10 \%$ over a period of 10-15 years. However, resin-dominated properties, such as interlaminar shear strength, are often more severely degraded by moisture [22,23]. It is shown in Ref. [12] that the stiffness and strength of a wide range of epoxy adhesives can degrade by as much as $90 \%$ and $70 \%$ respectively after ageing in humid conditions.

At joint level, the moisture-induced changes in material properties can considerably affect the behaviour of the joint up to failure [24]. Among these effects, the stability of interfacial adhesion in the presence of moisture is the most important factor in terms of the long-term durability of adhesively bonded FRP/steel joints [12]. This is mainly because the absorbed moisture forms substantially stronger bonds with the ultra-thin oxide layer covering the steel substrate than the adhesion forces at the adhesive/steel interface. This can lead to severe and irreversible changes caused by weakening or disrupting adhesion forces, cathodic or galvanic corrosion of the steel substrate. According to a recent state-of-the-art review [12], the strength of joints with unstable adhesive/steel interfaces in the presence of water might undergo degradation of as much as $60 \%$. Moisture can additionally induce sustained or cyclic swelling stresses at the interfaces of bonded assemblies [25]. As a result, time and exposure history are important factors that influence joint durability.

Recently, some researchers have investigated the combined effects of moisture and temperature on the mechanical performance of bonded FRP/steel joints [26-29]. Dawood and Rizkalla [26] conducted experiments using double-lap shear (DLS) specimens exposed to cyclic wet/dry scenarios in simulated seawater for up to six months. It was observed that the joint degradation was primarily due to the debonding of the steel/adhesive interface. Silane coupling agent was found greatly to stabilise the interface and prevent mechanical degradation at joint level. In another study, Nguyen et al. [27] immersed wet-layup CFRP/steel DLS joints in seawater at $20^{\circ} \mathrm{C}$ and $50{ }^{\circ} \mathrm{C}$ for up to a year. They found a direct analogy between the degradation of adhesive material and DLS joints. Jiang et al. [28] investigated the effect of the stress ratio on the durability of bonded GFRP/steel assemblies using an Arcan fixture. Tests were conducted after ageing specimens in water at $40{ }^{\circ} \mathrm{C}$ for four months. The results indicated that, while pure shear or peeling led to an approximate $60 \%$ strength reduction, mixedmode loading did not cause any degradation. The effect of the combined and separate application of wet thermal cycles and sustained loading was recently addressed by Agarwal et al. [29]. The authors found severe degradation in steel/CFRP single-lap shear joints subjected to the combined conditions, whereas their separate application had a negligible impact.

Although these studies have provided valuable and insightful information, there remain a number of aspects that require further investigation. Firstly, the utilised exposure durations were not long enough according to Karbhari [30], who suggests a minimum ageing time of 18 months. Secondly, the adhesive layer thickness of the tested joints $(0.1-0.5 \mathrm{~mm})$ were in orders of magnitude thinner than those used in typical bridge applications (1-6 mm) [12]. The adhesive layer thickness can greatly influence the long-term performance of these joints by altering diffusion, galvanic corrosion [31] and cathodic corrosion [32] rates. Furthermore, none of the available studies has distinguished the effects of each individual environmental factor (temperature, moisture and salt solutions) on joint durability.

The aim of this research is to provide an insight into the underlying mechanisms of the degradation of adhesively bonded FRP/ steel DLS joints exposed to harsh environmental conditions. The emphasis is placed on characterising the individual and combined effects of temperature, de-icing salt solutions and moisture on the mechanical behaviour of DLS joints. The DLS configuration is employed because of the ease of failure detection, availability in the literature and similarity in the stress state at the outer ends of the bond line in these specimens compared with those of strengthened steel girders [5]. In addition, the effect of FRP material was investigated by including joints fabricated with two types of FRP material. Last but not least, finite element simulations are conducted to identify correlations between the experimental observations and moisture distribution profiles in joints.

\section{Experimental programme}

\subsection{Materials}

Four materials were used to manufacture the specimens: epoxy adhesive, pultruded CFRP laminate, pultruded GFRP laminate and steel. The adhesive is a commercial bi-component structural epoxy adhesive, STO ${ }^{\circledR}$ BPE Lim 567. This adhesive was chosen due to its compatibility with steel substrate to avoid premature interfacial debonding failure of unaged joints. As discussed earlier, interfacial stability plays a significant role in the long-term performance of bonded joints and requires the careful assessment and selection of materials. The glass transition temperature of the cured adhesive was measured as $55{ }^{\circ} \mathrm{C}$ using dynamic mechanical analysis according to ASTM D7028-07 [33]. Unidirectional CFRP laminates were provided by Mostostal ${ }^{\circledR}$ and had a nominal thickness of $1.25 \mathrm{~mm}$ and a width of $50 \mathrm{~mm}$. The CFRP laminates consist of $82 \%$ (by weight) unidirectional carbon fibres embedded in an epoxy resin. The GFRP laminates were cut from $10 \mathrm{~mm}$ thick GFRP plates with a similar lay-up as in the flange of Asset deck profiles (FBD600) produced using a pultrusion process by Fiberline Composites ${ }^{\circledR}$. The lay-up consists of unidirectional rovings in the pultrusion direction, $0^{\circ} \pm 90^{\circ}$ woven mat layers and surfacing veils as the outermost layers to protect from environmental action. The section contains $67 \%$ E-glass fibres, by weight, embedded in an isophthalic polyester resin. Table 1 lists the measured mechanical properties of the materials used before environmental ageing. 
Table 1

Mechanical properties of the used materials.

\begin{tabular}{llll}
\hline Material & E-modulus [GPa] & Tensile strength [MPa] & Poisson's ratio \\
\hline Steel S355 & 200 & - & 0.3 \\
CFRP & 154 & 3030 & - \\
GFRP & 14 & 230 & - \\
Adhesive $^{\mathrm{a}}$ & 7.1 & 34 & 0.3 \\
\hline
\end{tabular}

a Data measured after 14 days' curing at room temperature.

\subsection{Specimens and test procedures}

A total of 192 specimens were prepared and tested to investigate the effects of ageing on constituent materials and bonded joints. The material-level tests comprised the tensile testing of adhesive dog-bone specimens, as well as CFRP and GFRP coupons. The effects of ageing on the adhesive are of interest as it is often regarded as the weak link in adhesively bonded assemblies. At joint level, the double-lap shear (DLS) configuration was chosen as an appropriate configuration as discussed earlier.

The constituent material tests included a total of 40 adhesive dog-bone specimens, 34 GFRP and 34 CFRP coupons that were prepared according to ASTM D638-10 and D3039/D3039M-14 respectively, see Fig. 1. For the adhesive material, five specimens were tested directly in the dry state, while all the other specimens were tested after environmental exposure for 260 and 530 days. The tests were conducted using a universal testing machine in the displacement-control mode and at a speed of $0.2 \mathrm{~mm} / \mathrm{min}$. A clipon extensometer was used to measure the axial strain in the narrow section of specimens. The results for specimens with failure at

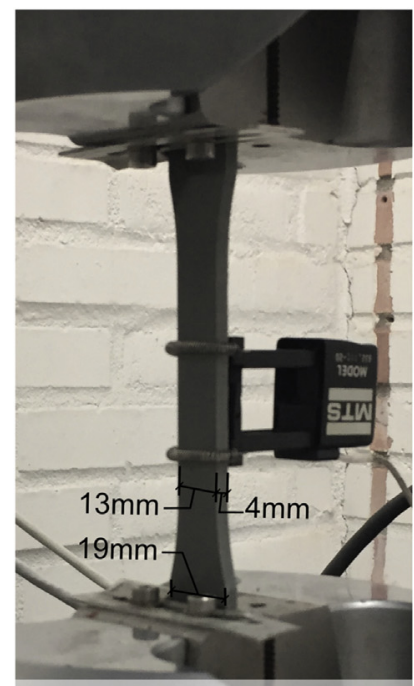

(a) Adhesive dog-bone

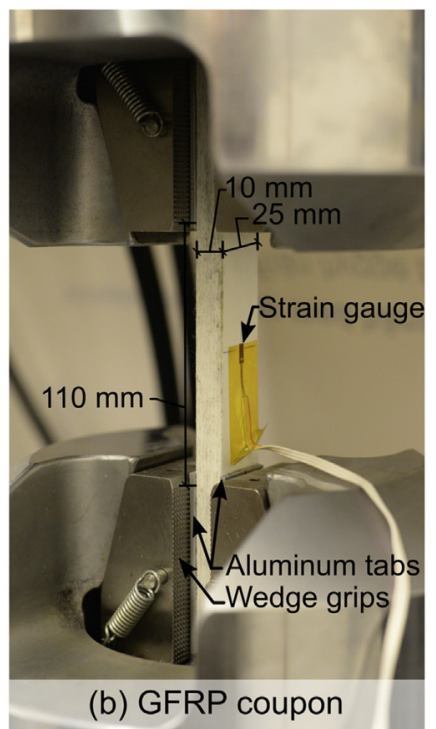

(b) GFRP coupon

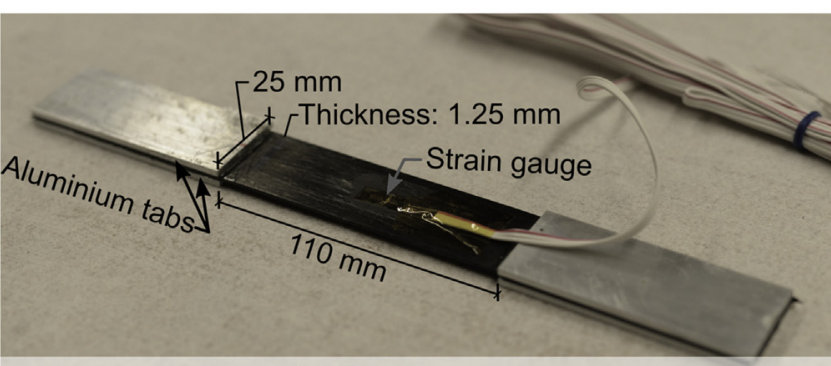

(c) CFRP coupon the location of imperfections such as trapped air bubbles were excluded. For the FRP material, four unaged specimens of each type were tested as control samples and all the other specimens were tested after ageing for 210 and 840 days. The tests were performed at a constant cross-head displacement rate of $0.5 \mathrm{~mm} / \mathrm{min}$. To prevent the coupons being crushed in the grips of the testing machine, aluminium tabs were glued to the ends of each FRP coupon prior to testing. The pressure of the grips was kept constant for each configuration. In addition, each specimen was equipped with a strain gauge to measure the axial strain during testing.

Fig. 2 depicts the schematics and photographs of the manufactured joint-level specimens. A total of 44 CFRP/steel and 40 GFRP/ steel double-lap shear (DLS) specimens were manufactured. As the free edges of GFRP plates in practice are not always a wet boundary condition (e.g. GFRP deck panels on steel girders), the edges of GFRP laminates were painted on six GFRP/steel specimens, see Fig. 2(b), in order to simulate an impermeable boundary condition. To prevent moisture diffusion from those faces, two layers of a waterresistant paint (JOTUN ${ }^{\circledR}$ Jotamastic 87 ) were applied. For each specimen type, three were tested before ageing and the rest after ageing for up to 1080 days (three years). The FRP laminates were chosen to be narrower than the steel plates to represent a typical field application in bridges where the entire flange may not be covered by FRP. The adhesive layer thickness was also designed to comply with different applications of FRPs in bridges where a thickness of $1-2 \mathrm{~mm}$ is often found in strengthening applications and $4-10 \mathrm{~mm}$ in GFRP-deck/girder connections. In order to ensure the uniform thickness of the adhesive layer and precise end detailing, i.e. without adhesive fillets at the ends, special moulding forms were used. Details of the fabrication process are given in Ref. [33]. Tests were carried out using a universal testing machine with a capacity of $250 \mathrm{kN}$ at a constant displacement rate of $0.1 \mathrm{~mm} / \mathrm{min}$. The axial displacement of the specimen, as well as its transverse displacement at the gap location, was recorded using a series of LVDT transducers. In addition, a high-resolution digital camera was used to monitor damage evolution during testing.

\subsection{Environmental conditioning}

Five environmental ageing conditions were selected, based on the service exposure of relevance for bridges. The glass transition temperature of the adhesive was taken as the limiting temperature with a margin of $10^{\circ} \mathrm{C}$. These environments included:

(i) 45RH: exposure to $45^{\circ} \mathrm{C}$ at $95 \%$ relative humidity,

(ii) $45 \mathrm{DW}$ : immersion in $45^{\circ} \mathrm{C}$ distilled water,

(iii) $45 \mathrm{SW}$ : immersion in $45^{\circ} \mathrm{C}$ salt water,

(iv) 20DW: immersion in $20^{\circ} \mathrm{C}$ distilled water,

(v) $20 \mathrm{SW}$ : immersion in $20^{\circ} \mathrm{C}$ salt water.

The salt-water solution was included to study the effects of deicing salt solutions that are often found in bridge environments and was obtained by mixing $5 \%$ by weight $\mathrm{NaCl}$ salt with distilled water. The specimens were put in immersion tanks with a constant temperature of $20^{\circ} \mathrm{C}$ and $45^{\circ} \mathrm{C}$ and were removed after various exposure durations for tensile testing. The ageing of the $45 \mathrm{RH}$ series was achieved by using an environmental chamber with controlled relative humidity and temperature fixed at $95 \%$ and $45^{\circ} \mathrm{C}$, respectively.

\section{Finite element analysis}

\subsection{Moisture diffusion modelling}

As discussed earlier, the presence of moisture in an adhesively

Fig. 1. Configurations of material-level tests. 


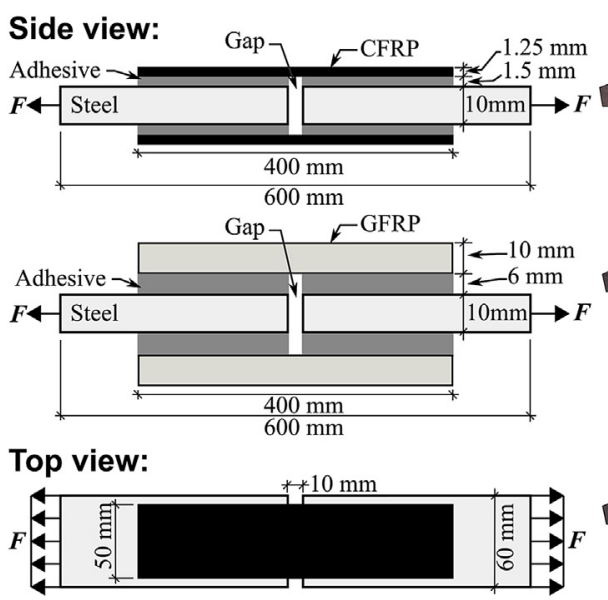

(a)

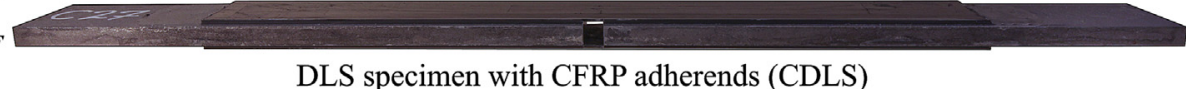

DLS specimen with CFRP adherends (CDLS)

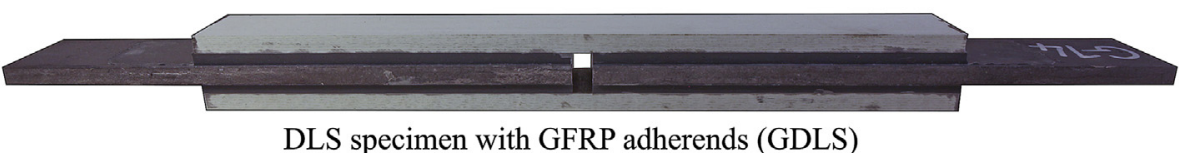

DLS specimen with GFRP adherends (GDLS)

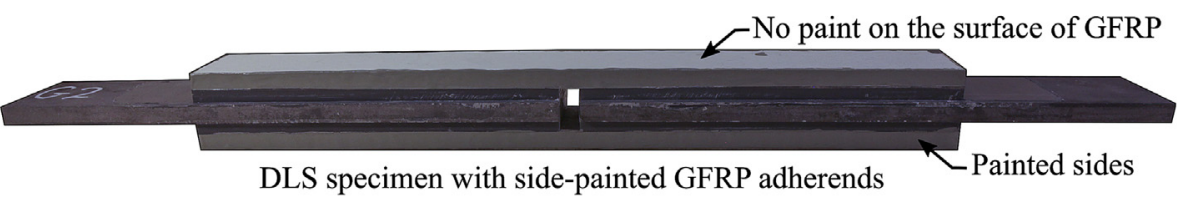

(b)

Fig. 2. (a) Schematics of double-lap shear joints, (b) photographs of manufactured specimens.

bonded join can substantially affect its mechanical performance. For this reason, information about the moisture profile (i.e. moisture distribution pattern) in a joint can greatly help understand its behaviour during residual strength tests. However, this information cannot be obtained using the well-established gravimetric measurement approach due to its many limitations, or more advanced EIS method due to its shortcomings regarding joints with permeable adherends (such as FRPs).

One solution is to utilise numerical methods, such as the finite element (FE) analysis, in conjunction with material-level experimental data, namely moisture-diffusion parameters. In this regard, for bonded FRP joints, mass-diffusion analysis with varying solubility for different materials is favoured over heat-transfer analysis $[14,34]$. In this paper, the commercial FE software Abaqus ${ }^{\circledR} 6.13$ was used. The joints were modelled as 3D objects. Transient massdiffusion analyses were conducted. The moisture concentration of all the surfaces of permeable materials that are in contact with moisture were set to be fully saturated as the boundary conditions. The adopted analysis method and material input data were shown by the authors to yield accurate predictions in Ref. [14]. Table 2 lists the diffusion coefficients (D) and moisture content at saturation $\left(\mathrm{M}_{\infty}\right)$ that are used in the FE analysis (data taken partly from Ref. [14]).

\section{Results and discussion}

\subsection{Effect of ageing on materials}

\subsubsection{CFRP}

As can be seen from Table 2, the moisture ingress into the CFRP material is considerably slower compared with other constituent materials. The low permeability of the used CFRP material could be attributed to its high fibre content, resin type and manufacturing quality. Fig. 3 shows the effect of various ageing scenarios on the Emodulus and tensile strength of CFRP. For each ageing condition, tests were performed after exposure for 210 and 840 days (seven and 28 months respectively). The error bars show the scatter range of three replicas tested in each group. As is apparent from Fig. 3(a), the modulus of elasticity is hardly affected by any of the ageing conditions, even after 840 days of exposure. Given the fibre dependence of the E-modulus of unidirectional composites, as well as the stability of carbon fibres in the presence of moisture [11], this observation can be justified.

The tensile strength, on the other hand, was significantly degraded with increased exposure duration and the severity of the ageing condition, see Fig. 3(b). This observation can be explained by the change in failure mode observed during tests, see Fig. 4. With increased exposure, the failure shifted from a rupture mode to the interlaminar failure of CFRP at the grips. Interlaminar shear strength is a resin-dominated property that is highly susceptible to environmental degradation. Although the tensile coupon test is not an appropriate configuration for the quantitative assessment of interlaminar shear strength, it is possible to evaluate the degradation trends qualitatively, as all the tested CFRP coupons were subjected to the same pressure at the grips. In this regard, at a given temperature, the short-term immersion in distilled water is found to be more damaging than salt water. This is believed to be due to the moisture-diffusion characteristics that would result in a higher near-surface moisture concentration of the specimens immersed in distilled water compared with salt water at the same temperature (see Table 2). Consequently, the rate of accumulation of salt water molecules at resin/fibre interface close to the surfaces of CFRP

Table 2

Moisture diffusion parameters of the used materials.

\begin{tabular}{|c|c|c|c|c|c|c|c|c|}
\hline \multirow[t]{2}{*}{ Condition } & \multicolumn{4}{|l|}{ GFRP } & \multicolumn{2}{|l|}{ CFRP } & \multicolumn{2}{|l|}{ Adhesive $^{\mathrm{b}}$} \\
\hline & $\mathrm{D}_{\mathrm{x}}^{\mathrm{a}}$ & $\mathrm{D}_{\mathrm{y}}$ & $D_{z}$ & $\mathrm{M}_{\infty}[\%]$ & $\mathrm{D}\left(\times 10^{-4}\right)$ & $\mathrm{M}_{\infty}[\%]$ & $\mathrm{D}\left\{\mathrm{D}_{2}\right\}$ & $\mathrm{M}_{\infty}\left\{\mathrm{M}_{\infty, 1}\right\}[\%]$ \\
\hline 45DW & 11.823 & 8.154 & 3.977 & 5.05 & 3.8 & 1.05 & $0.032\left\{4.2 \times 10^{-4}\right\}$ & $1.77\{1.40\}$ \\
\hline 45SW & 6.958 & 4.659 & 2.225 & 5.05 & 6.8 & 0.80 & 0.037 & 1.34 \\
\hline 20DW & 1.019 & 0.996 & 1.820 & 5.22 & 3.2 & 0.47 & 0.003 & 1.66 \\
\hline 20SW & 5.149 & 2.585 & 0.734 & 5.00 & 4.3 & 0.38 & 0.003 & 1.36 \\
\hline $45 \mathrm{RH}$ & 3.552 & 7.759 & - & 0.23 & 10 & 0.58 & 0.052 & 1.10 \\
\hline
\end{tabular}

a All the diffusion coefficient values are in [ $\mathrm{mm}^{2} /$ day] unit.

b Additional values for dual-Fickian diffusion are given in brackets. 


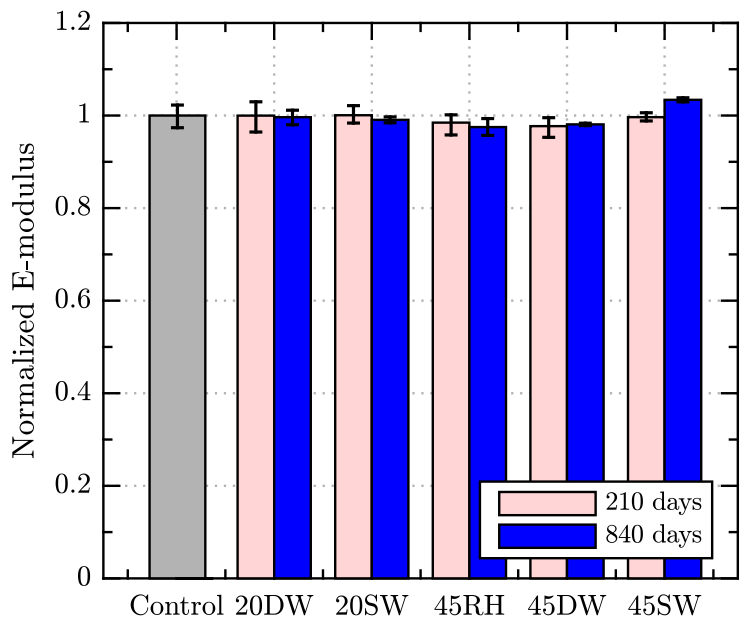

(a)

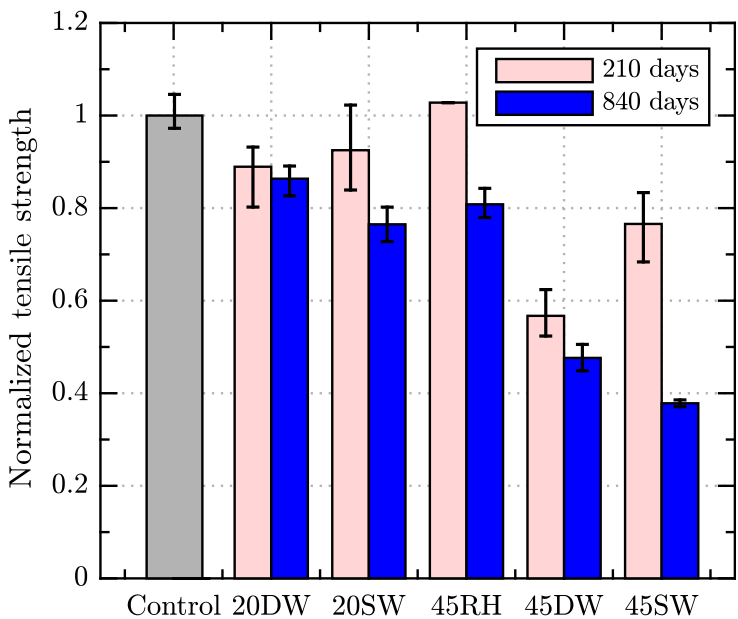

(b)

Fig. 3. Effect of ageing on the normalized mechanical properties of CFRP: (a) E-modulus, (b) tensile strength.

coupons becomes less than that of distilled water. Hence, as the damage evolution at resin/fibre interface depends on both exposure time and solution concentration, the lower degradation of

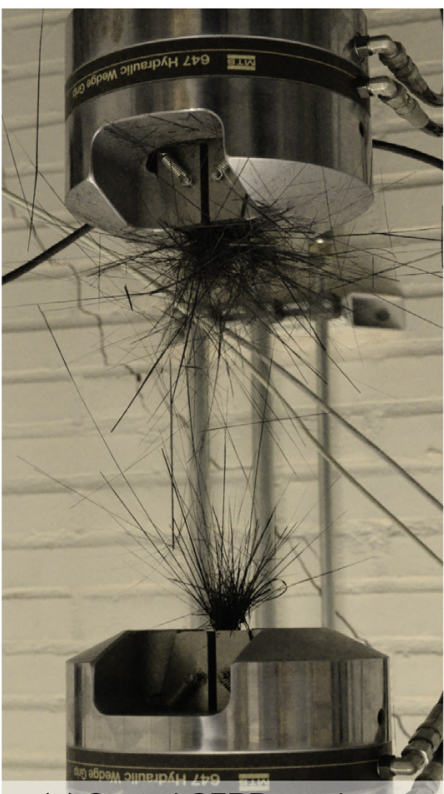

(a) Control CFRP specimen

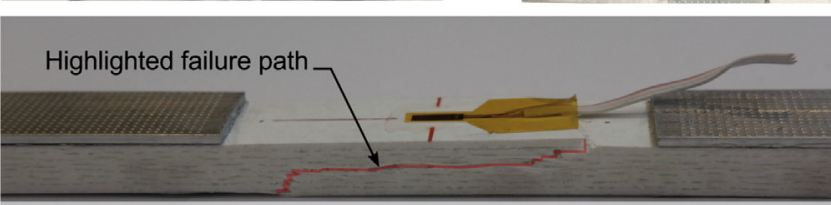

(c) Control GFRP specimen

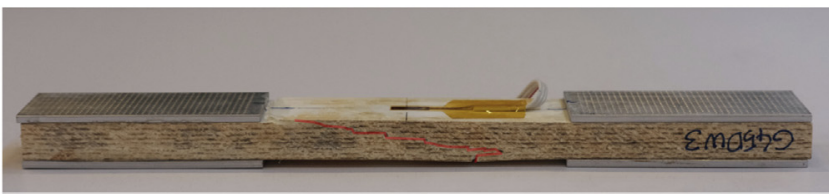

(d) Aged at 45DW for 840 days

Fig. 4. The change in failure mode of CFRP coupon tests after environmental ageing. interlaminar shear strength after exposure for 210 days in saltwater compared to distilled water is justified. However, with longer exposure and higher solution concentrations, salt water caused more degradation compared with distilled water. The more damaging effects of salt water compared with distilled water or vapour on the interlaminar strength of FRPs have previously been reported by some researchers and are often attributed to resin/fibre interface damage (see, for example, [11]). Moreover, as moisture diffusion is highly dependent on its concentration and temperature, the greatest degradation is found for immersion conditions at $45^{\circ} \mathrm{C}$.

\subsubsection{GFRP}

The GFRP material is extremely permeable, with the fastest diffusion rates among those listed in Table 2. In fact, all the GFRP coupons would reach moisture saturation less than a month after exposure [14]. The effect of ageing on the normalized E-modulus and tensile strength of GFRP coupons is plotted in Fig. 5. It is noticeable that, similar to CFRP coupons, ageing has significantly affected the strength, whereas the average degradation of the Emodulus is generally less than $10 \%$. All the tested GFRP coupons exhibited a similar failure mode, as shown in Fig. 4(c) and (d). As can be seen, tensile strength is governed by a combination of fibre and resin failure. In addition to the common susceptibility of resins to ageing, glass fibres (unlike carbon fibres) may also degrade in the presence of moisture with prolonged exposure. As a result, while the initial reduction in strength is believed to be a consequence of degrading resin and fibre/resin interface [35], its further reduction after 840 days can also be attributed to damaged glass fibres [36].

It is also interesting to note that, despite the highest strength reductions after immersion in salt solution or water at $45{ }^{\circ} \mathrm{C}$, exposure to humidity (vapour) at the same temperature has resulted in the lowest reduction of all. This observation is due to the large difference in the saturation moisture content of these two series ( $5 \%$ vs. $0.23 \%$ respectively) and highlights the importance of moisture concentration as a prerequisite of higher temperature to cause greater damage.

\subsubsection{Epoxy adhesive}

The effects of moisture on the mechanical properties of epoxy adhesive are plotted in Fig. 6 . The results are reported based on the moisture content of the dog-bone specimens at the time of testing, as it is well known that there is a direct relationship between 


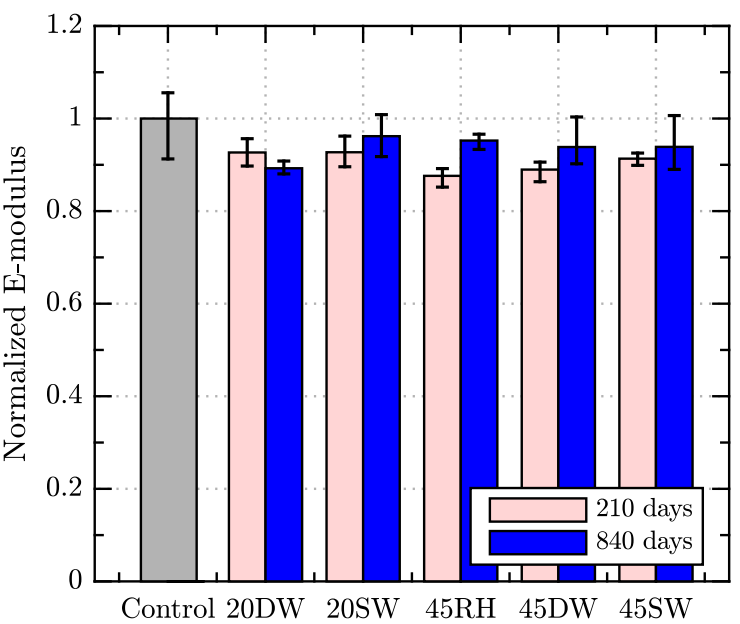

(a)

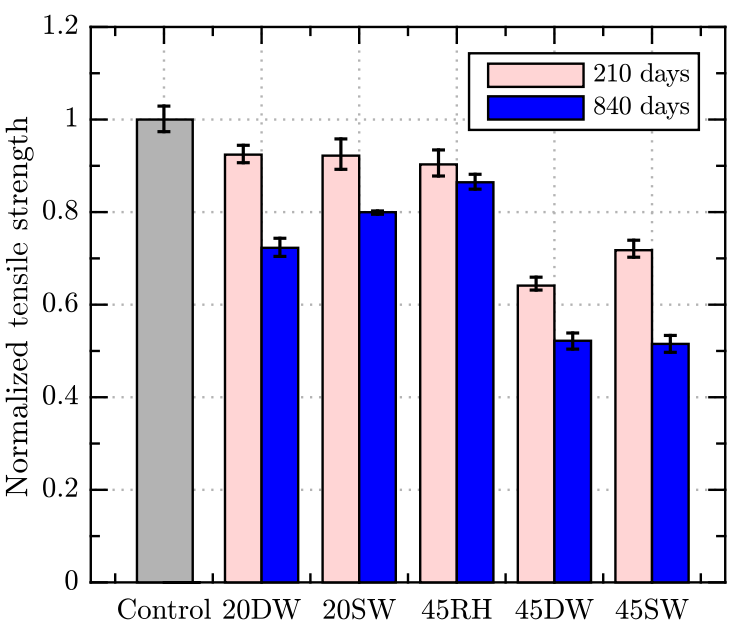

(b)

Fig. 5. Effect of ageing on the normalized mechanical properties of GFRP: (a) E-modulus, (b) tensile strength.

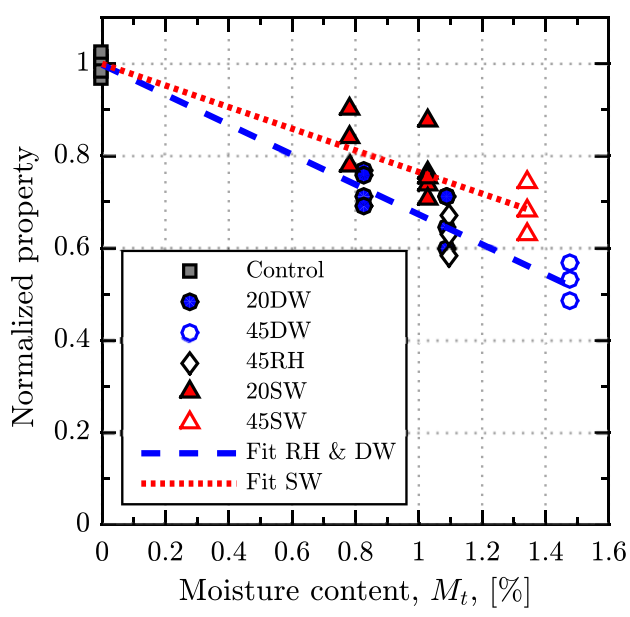

(a) E-modulus

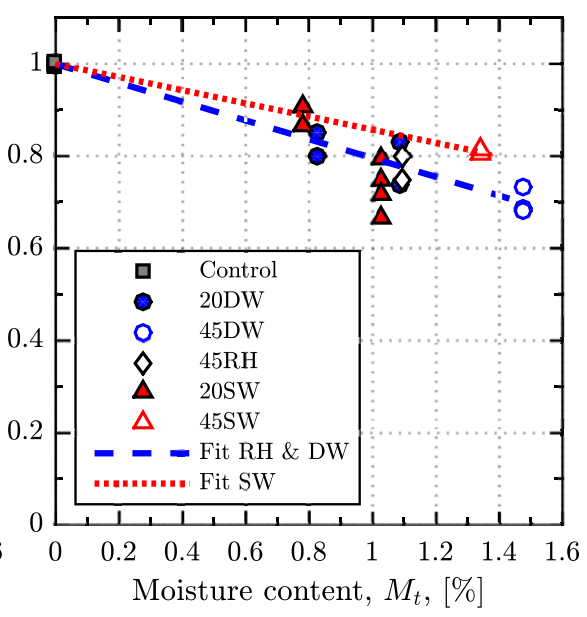

(b) Tensile strength

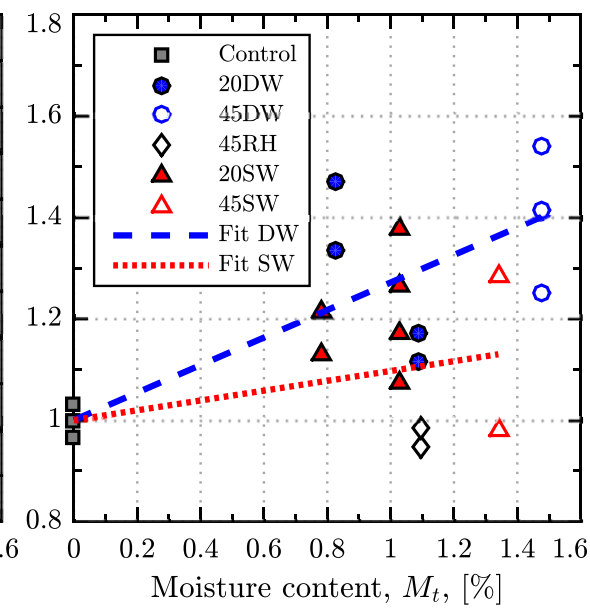

(c) Ultimate strain

Fig. 6. Effect of ageing on the normalized mechanical properties of epoxy adhesive: (a) E-modulus, (b) tensile strength, (c) ultimate strain.

moisture content and mechanical properties. The moisture content $\left(M_{t}\right)$ of the dog-bone specimens at the time of testing was derived by $3 \mathrm{D}$ mass-diffusion simulations using the input data listed in Table 2. To double-check the accuracy of the FE results, gravimetric measurements were also carried out for some of the specimens and it was found that the deviation was less than $5 \%$. The FE analysis revealed that only the specimens aged at $45{ }^{\circ} \mathrm{C}$ reached their moisture saturation level after 260 days. For this reason, for specimens aged at $20^{\circ} \mathrm{C}$, an additional series was also tested after 530 days of exposure. Although the latter series reached higher moisture contents, the saturation level was still not achieved.

Fig. 6(a) shows the changes in the E-modulus of the adhesive with increasing moisture content. The best fit to the data was estimated considering only the control and fully saturated specimens, i.e. aged at $45{ }^{\circ} \mathrm{C}$. The results clearly show a reduction in Emodulus with increasing moisture content. The reduction rate is, however, lower for the salt solution than for distilled water or vapour. At ultimate moisture content levels, the loss of E-modulus is around $32 \%$ and $48 \%$ for the "SW" and "RH \& DW" series respectively. In addition, it can be seen that the elastic moduli of all specimens aged at $20^{\circ} \mathrm{C}$ for 260 and 530 days can be accurately predicted by the obtained fits. This observation confirms that, for this adhesive, ageing at $45^{\circ} \mathrm{C}$ is able safely to accelerate the moisture diffusion without causing undesirable effects [37] on its mechanical properties.

As can be seen in Fig. 6(b), environmental ageing has also degraded the strength of adhesive specimens. While the trends are similar to those observed for the modulus of elasticity, the ultimate reduction magnitudes are smaller for strength and are around 19\% and 30\% for the "SW" and "RH \& DW" series respectively. Moreover, the ultimate strain is found to increase with moisture content. The only exception is the "RH" series that exhibited almost no change. It can therefore be concluded that both the moisture content and the state of diffusing medium (vapour or liquid) are important when assessing the failure strain of adhesives. This observation explains the inconclusive effects of moisture on failure strain that was reported for a wide range of adhesives in Ref. [12].

\subsection{Moisture distribution prediction in joints}

The predicted moisture content summed over the volume of adhesive layer in DLS specimens is plotted in Fig. 7. As can be seen, 
the absorbed moisture at the same temperature and time is significantly higher in GFRP/steel specimens compared with CFRP/ steel specimens. This observation could be explained by the high permeability of the GFRP material compared with the almost impermeable CFRP laminates, which provides an additional boundary condition for moisture uptake. This permeability can be attributed to the structure of the two composite materials and the types of fibre and matrix used to manufacture them. Shortly after exposure (approximately two to four weeks, depending on the exposure condition), GFRP becomes saturated and provides new and considerably shortened moisture diffusion routes through the thickness of the adhesive layer.

Fig. 8 shows contour plots of normalized moisture concentration in the adhesive layer of GFRP/steel specimens conditioned in 20SW and $45 \mathrm{SW}$. The moisture concentration is normalized with respect to the saturation moisture content of adhesive in each environment. Only a quarter of the adhesive is shown due to symmetry.

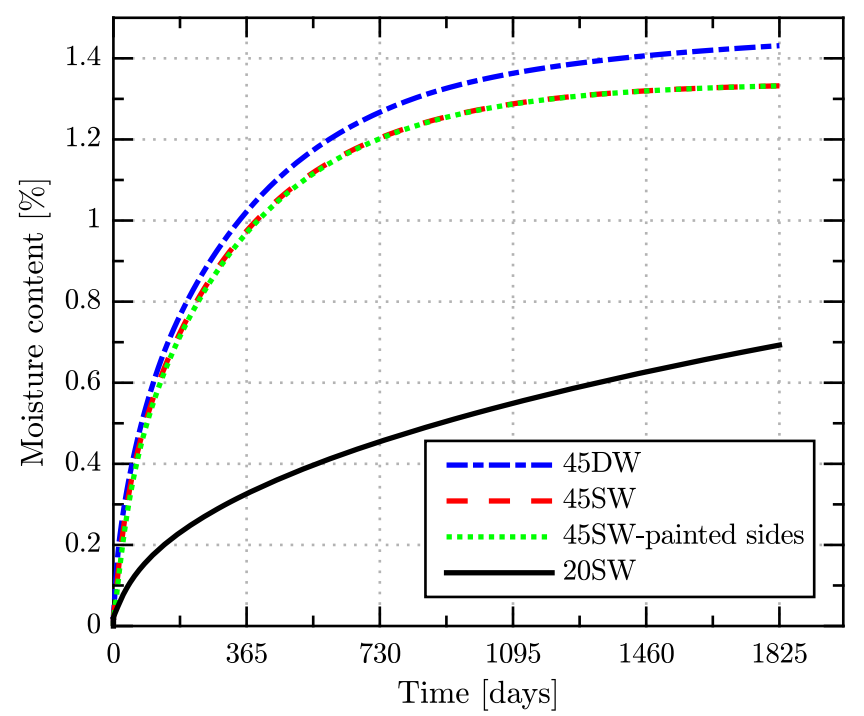

(a)

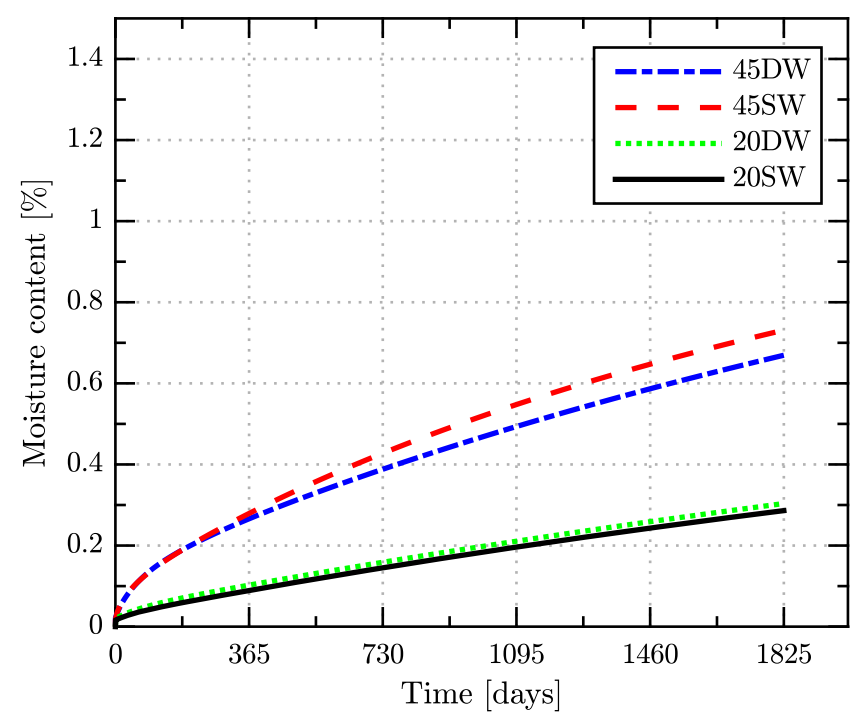

(b)

Fig. 7. Predicted total moisture content of the adhesive layer in DLS specimens: (a) GFRP/steel, (b) CFRP/steel.
Due to the direct moisture contact, the normalized concentration is higher closer to the external boundaries of the adhesive layer. Nevertheless, as discussed earlier, as a result of the additional moisture diffusion from the GFRP adherend, the moisture concentration also varies in the thickness direction. For instance, as can be seen in Fig. 8 for the 20SW condition, while the portion of the adhesive layer close to steel is almost dry after one year of exposure, the moisture concentration is significantly higher in the vicinity of GFRP. A clear consequence of variable moisture content in the adhesive material, given the dependence of its mechanical properties on moisture content, would be a highly inhomogeneous adhesive layer through the thickness and along the bond line. The consequences of this phenomenon will be discussed in more detail in Section 4.3.1. It is also noteworthy that the predicted moisture content of the adhesive layer is not affected by painting the edges of GFRP laminates, see Fig. 7(a). This is mainly due to the fact that the water ingress from the GFRP into the adhesive governs the overall moisture uptake of the adhesive layer. This observation implies that painting the edges of GFRP had no noticeable effect on the mechanical response of GFRP/steel joints.

Another observation from Fig. 7(b) is that, after almost one year, the moisture content of the adhesive layer in CFRP/steel specimens aged in 45SW exceeds that of the ones aged in 45DW. This observation can be explained in the light of the predicted moisture profiles in CFRP/steel joints illustrated in Fig. 9. Since the saturation moisture content and diffusion rates of the adhesive are higher than those of the CFRP in all environments (see Table 2), a portion of the diffused moisture in the adhesive will be transported into the adjacent CFRP material. This, in turn, would result in a loss of moisture content in the adhesive layer. This process occurs to the greatest degree in the 45DW condition due to the highest associated moisture saturation level of the CFRP material.

Fig. 10 shows a comparison of the normalized moisture concentration of CFRP along its interface with the adhesive at various exposure durations in 45DW and 45SW. As can be seen, at similar exposure durations and temperature, the normalized moisture concentration is higher in salt water than in distilled water. This observation can be also attributed to the interfacial moisture transport from the adhesive to the CFRP material. In this regard, the moisture available at the interface of CFRP and adhesive is limited by the diffusion rate of the adhesive material, which is merely a function of temperature [14]. Moreover, given the higher moisture saturation content of CFRP in 45DW compared with 45SW, a larger amount of moisture is required in $45 \mathrm{DW}$ for an equal increase in normalized moisture concentration. For this reason, at the same exposure temperature and time, the normalized moisture saturation would be higher for the condition that gives a lower moisture saturation content for CFRP, i.e. 45SW. Given the large degradation of the interlaminar shear strength of CFRP upon ageing, its moisture concentration at the interface with adhesive is expected strongly to affect the strength of the bonded joints (Section 4.3.3).

\subsection{Effect of ageing on joints}

\subsubsection{Failure modes}

Fig. 11 shows images of DLS specimens directly after removal from the conditioning tanks. It is apparent that the steel plates were significantly corroded. Visual inspections revealed that the corrosion was more severe at $45{ }^{\circ} \mathrm{C}$ compared with $20{ }^{\circ} \mathrm{C}$ after similar ageing durations. The deposition of corrosion products on the surfaces of FRP adherends led to the slight discoloration of both CFRP and GFRP materials. However, no signs of wear or the debonding of FRP laminates were observed during the inspections. It was only in the case of prolonged exposure, i.e. after one year, of GFRP/steel specimens that cracks were visually detected in the 

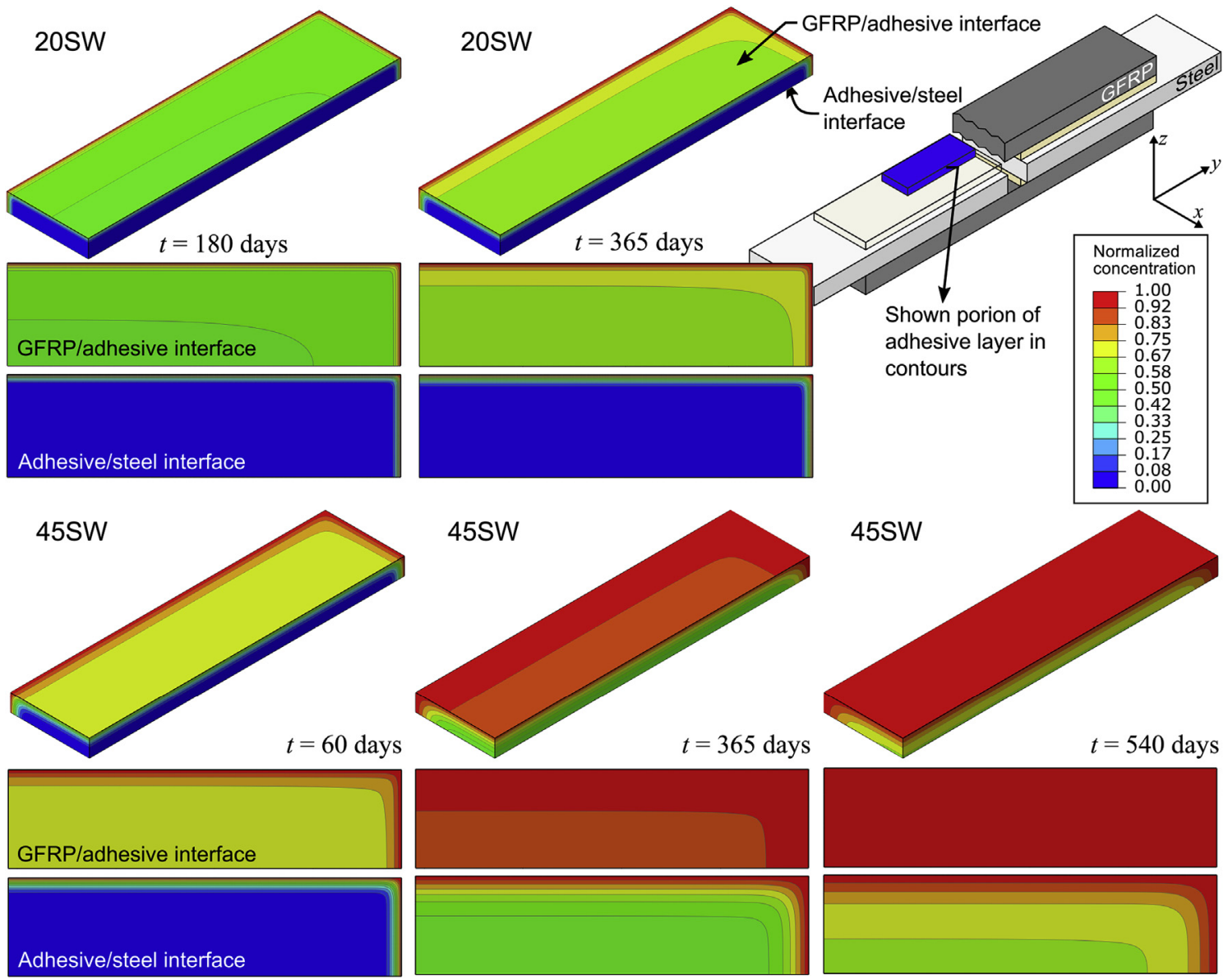

Fig. 8. Contour plots of moisture distribution profiles in the adhesive layer of GFRP/steel specimens at various exposure times (t).

adhesive layer, see Fig. 12. As can be seen, these cracks were directed longitudinally and located very close to the GFRP laminates. The cracks were also accompanied by the dispersed discoloration of the adhesive material. The formation of these cracks in the GFRP/steel series was limited to the specimens aged for more than 180 days in 45DW and 540 days in 45SW. One explanation of this phenomenon could be the non-uniform moisture distribution in the adhesive layer in GFRP/steel specimens, as discussed in Section 4.2. Given that moisture uptake is able to induce volumetric expansion (i.e. swelling), the swelling of the wet portion of the

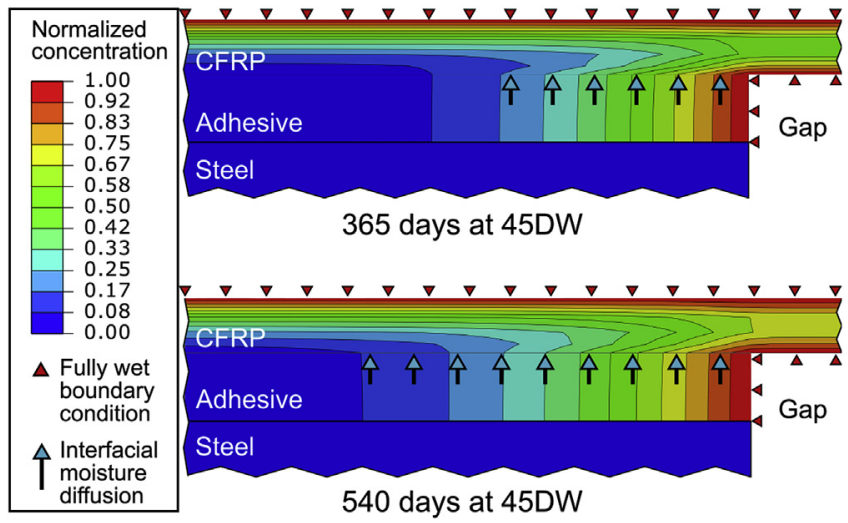

Fig. 9. Contour plots of through-thickness moisture distribution close to the gap of CFRP/steel specimens along the centre line of the joint. adhesive could have led to the formation of shear stresses that caused these cracks. The deleterious effects of swelling have also been outlined by other researchers and they are believed to exert additional shear stresses [38-40]. As swelling is directly proportional to the volume of diffused water, these cracks were first

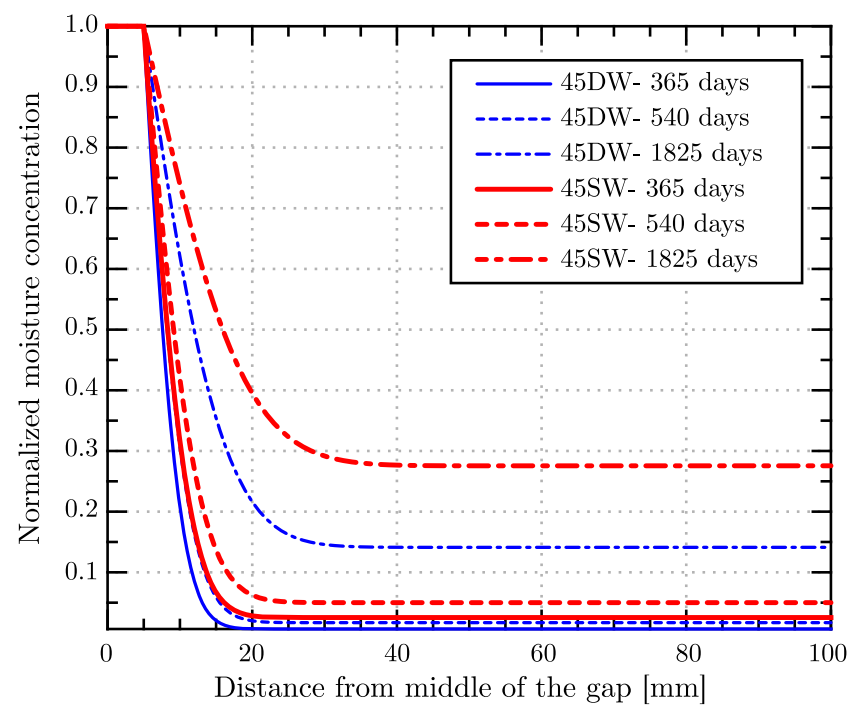

Fig. 10. Moisture concentration of the CFRP at the CFRP/adhesive interface along a path located at the mid-width of the joint. 


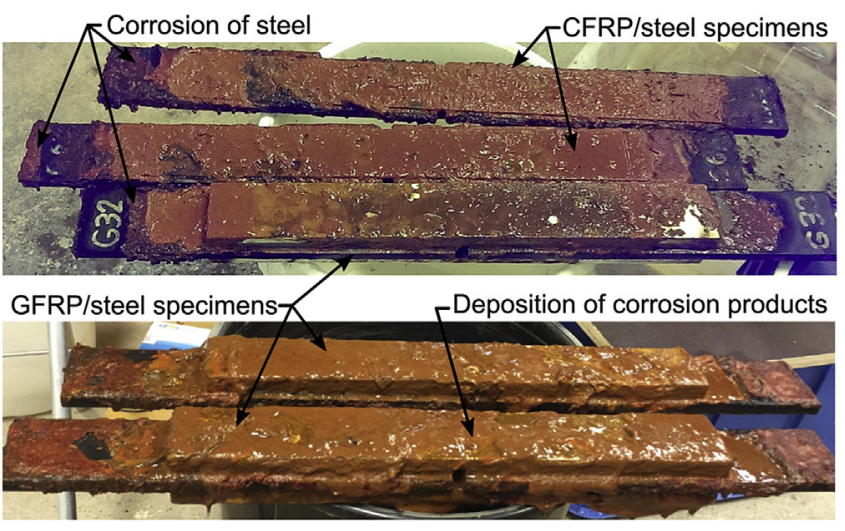

Fig. 11. DLS specimens after environmental ageing.

discovered for the condition with the fastest through-thickness diffusion rate for GFRP and the highest saturation moisture content in adhesive, i.e. 45DW.

The failure of adhesively bonded FRP/steel joints can be governed by a number of different modes including (i) cohesive failure, (ii) delamination failure of FRP and (iii) interfacial debonding failure. In addition, failure may occur due to any combination of the aforementioned modes. Combined failure modes can be a result of an inhomogeneous material state and/or an asymmetrical failure mechanism. In this study, careful monitoring of the DLS specimens during testing revealed that failure was always initiated in the adhesive end close to the gap area where the principal stress reaches its maximum, see Fig. 13. Given that the stiffness of the steel plate relative to that of CFRP or GFRP laminates is greater than one, the failure mechanism observed during experiments is reasonable according to [41]. Moreover, to exclude the effects of asymmetrical load transfer (after initial crack initiation on one side of the specimen) on failure mode, the assessments of failure surface are limited to areas close to the gap (triggering failure mode).

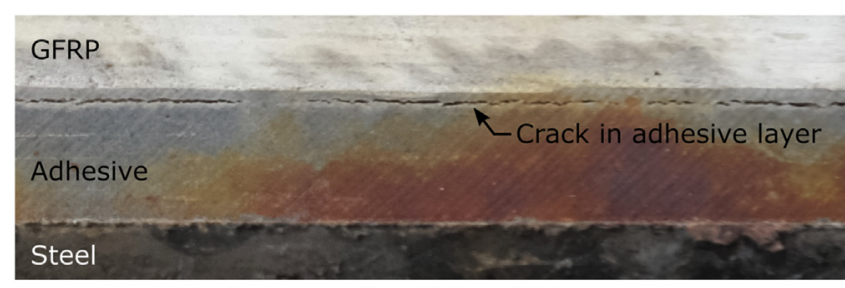

Aged at 45DW for 365 days
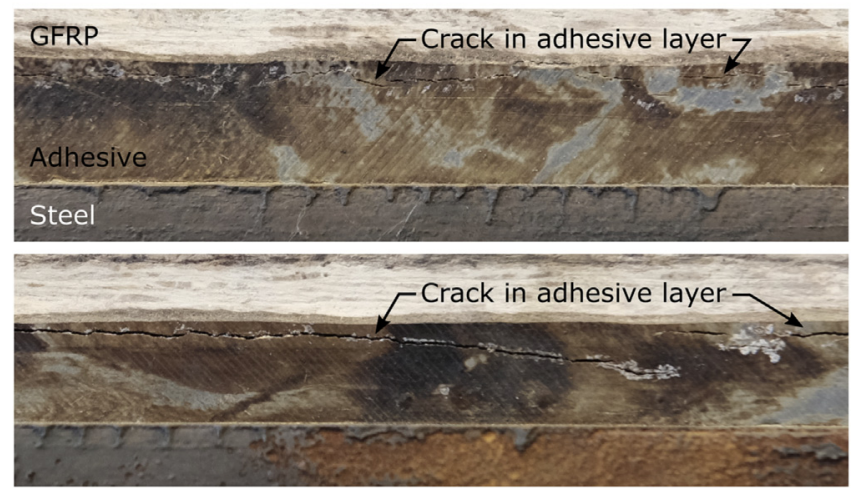

Aged at $45 \mathrm{SW}$ for 540 days

Fig. 12. Cracks that appeared in the adhesive layer of GFRP/steel specimens upon prolonged ageing.

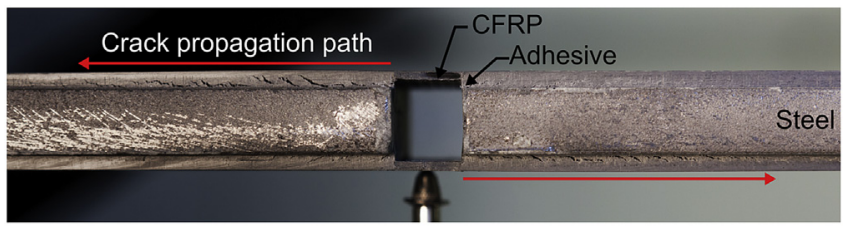

(a)

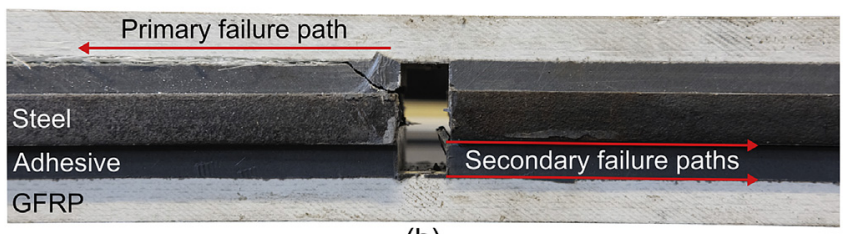

(b)

Fig. 13. Failure mechanism of control DLS specimens during residual strength tests: (a) CFRP/steel, (b) GFRP/steel specimen.

The failure mechanism of CFRP/steel control specimens is depicted in Fig. 13(a). As can be seen, two dominant cracks were initiated on the opposite sides of the gap in a diagonal pattern. Postfracture analysis of the failure surfaces revealed that all the control CFRP/steel specimens exhibited cohesive failure as the triggering failure mode, see Fig. 14(a). This observation confirms good bond quality which ensures high joint efficiency and ductility. Cohesive failure was also the triggering failure mode of all the specimens aged at $20^{\circ} \mathrm{C}$, except for one which failed due to CFRP delamination. However, the cohesive failure mode changed to a number of other failure modes upon ageing at $45^{\circ} \mathrm{C}$, as illustrated in Fig. 14(b-e). In particular, ageing in $45 \mathrm{SW}$ caused the fastest change in failure mode to combined interfacial/interlaminar CFRP failure after only 120 days of exposure, see Fig. 14(b). After 240 days of exposure, this failure mode changed to the interlaminar failure of CFRP at its interface with the adhesive, see Fig. 14(e). In comparison, the failure mode of CFRP/steel specimens aged for 540 days in 45DW remained as interfacial/cohesive. The failure of joints in 45SW due to the interlaminar failure of CFRP further confirms the importance of the normalized moisture concentration of CFRP that was discussed in Section 4.2 (see also Fig. 10). It should be mentioned that, despite the visible corrosion of exposed steel parts, no corrosion of steel in the bonded areas was detected by visual inspection after testing.

As is apparent from Fig. 13(b), the behaviour of control GFRP/ steel specimens was governed by a combination of failure mechanisms. The primary failure was mainly composed of the delamination of the GFRP at the $0^{\circ} \pm 90^{\circ}$ mat layer and finishing layer, see Fig. 15(a). This was accompanied by a sharp drop in load during the tests. After this point, the load was transferred through only one of the laminates. This asymmetrical load transfer led to the out-ofplane bending of the specimen (i.e. increased transverse deformation) that caused secondary failure. As a result, the reported failure modes are only based on the primary failure location, as it is representative of the joint in-service behaviour. In this regard, immersion in $20^{\circ} \mathrm{C}$ salt water (20SW) for up to one year did not cause any changes in the failure mode compared with control specimens, see Fig. 15(b). The failure mode of GFRP/steel specimens immersed in $45{ }^{\circ} \mathrm{C}$ salt water $(45 \mathrm{SW})$ for up to one year was similarly caused by the interlaminar-shear failure of the GFRP laminate. However, increasing the exposure duration to 540 days shifted the primary failure location to the adhesive layer close to GFRP, i.e. cohesive failure, Fig. 15(c). Painting the edges of the GFRPs did not cause any further change in this behaviour. Nevertheless, ageing in 45DW accelerated this process; the interlaminar failure 


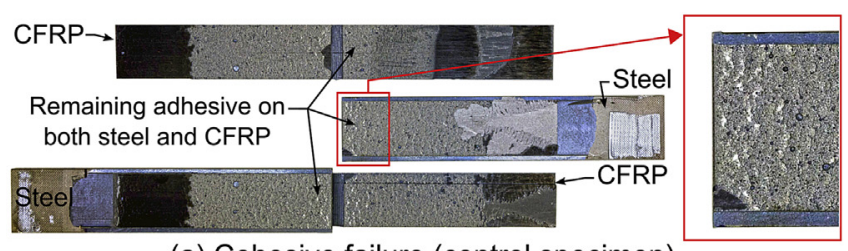

(a) Cohesive failure (control specimen)

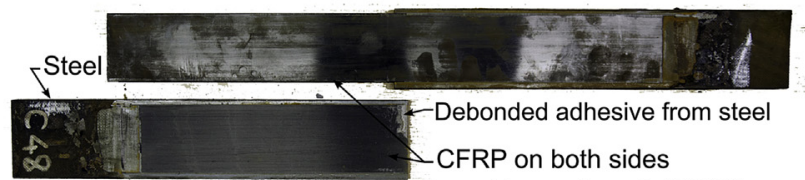

(b) Interfacial/interlaminar failure (4 months at $45 \mathrm{SW}$ )

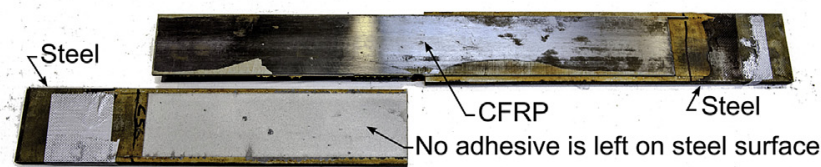

(c) Interfacial failure (6 months at $45 \mathrm{SW}$ )

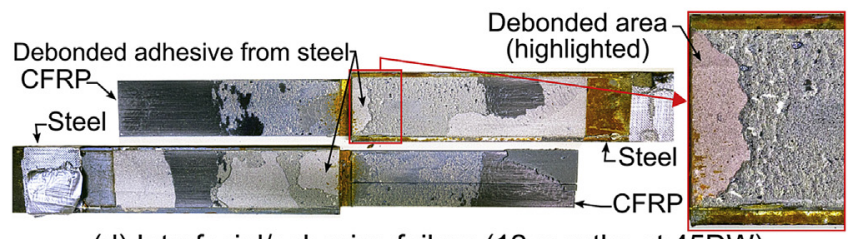

(d) Interfacial/cohesive failure (12 months at 45DW)

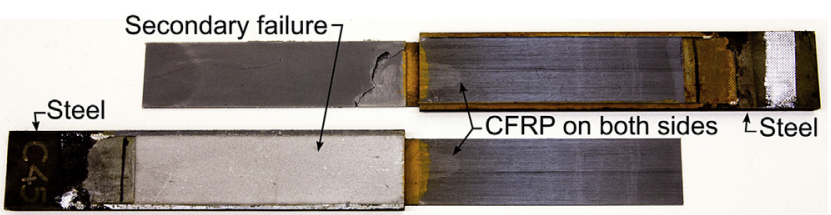

(e) Interlaminar CFRP failure (8 months at $45 \mathrm{SW}$ )

Fig. 14. Examples of fracture surfaces and failure modes of CFRP/steel specimens.

mode changed to cohesive failure after only 180 days of exposure, Fig. 15(d) and (e).

\subsubsection{Joint stiffness}

The stiffness of DLS joints is evaluated by studying the relationship between axial load and axial displacement. Fig. 16 shows this relationship for control DLS specimens. As can be seen, the load increases almost linearly in zone I, non-linearly in zone II, at the end of which a maximum load is reached, and remains almost constant afterwards (zone III). It is shown by the authors in Ref. [42] that, from a damage point of view, zone I is the state of no damage, zone II is the damage development state and zone III corresponds to crack propagation. So, to evaluate the stiffness of DLS joints prior to any damage, a stiffness factor is defined as the slope of the loaddisplacement curve calculated using two points within zone I. For the sake of consistency, these points were taken at axial displacements corresponding to 0.1 and $0.3 \mathrm{~mm}$ for all specimens. Moreover, In order to define a consistent failure criterion for the tested joints, the changes in joint stiffness during testing are further evaluated by differentiating the load-displacement curves. In this regard, the load at the point where it drops suddenly or stiffness becomes zero for the first time (horizontal tangent line) is taken as the ultimate failure load and is subsequently used to assess the bond strength.

The effect of environmental ageing on the initial stiffness of DLS

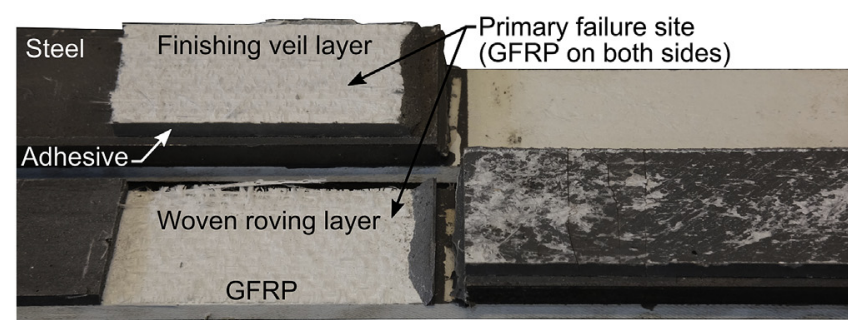

(a) Control GFRP/steel specimen

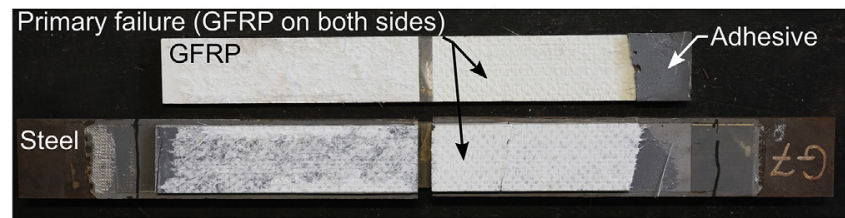

(b) Interlaminar GFRP failure (12 months at 20SW)

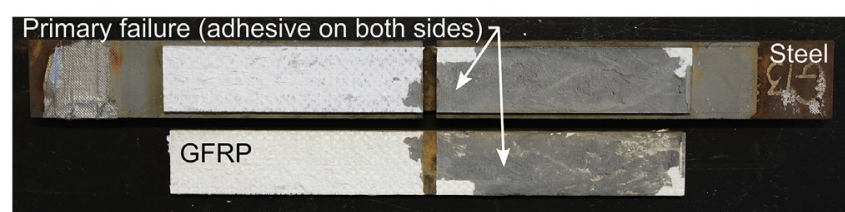

(c) Cohesive failure (18 months at 45SW)

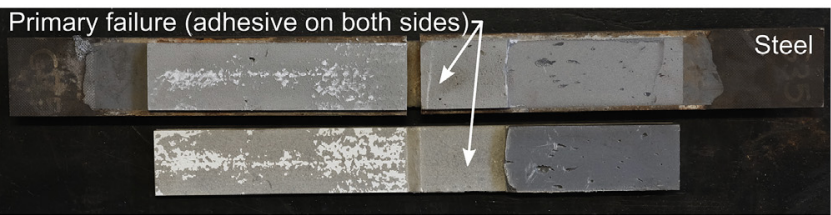

(d) Cohesive failure (6 months at 45DW)

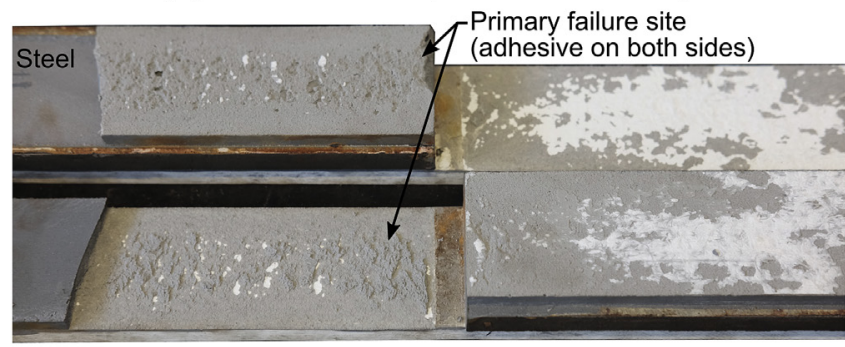

(e) Cohesive failure (18 months at 45DW)

Fig. 15. Examples of fracture surfaces and failure modes of GFRP/steel specimens.

joints is plotted in Fig. 17. As can be seen, the reductions in the initial joint stiffness in GFRP/steel specimens are noticeably larger than that of CFRP/steel specimens. There are two main arguments that can be put forward to explain this observation. Firstly, the data presented in Fig. 5(a) appear to suggest that the modulus of elasticity of GFRP is more susceptible to degradation compared with CFRP, cf. Fig. 3(a). Secondly, considerably faster moisture diffusion into the adhesive layer of GFRP/steel specimens decreases its overall stiffness and thus leads to a further reduction in joint stiffness. A closer look at the data indicates that, while ageing at 20SW for up to three years caused no significant variation (approx. $4 \%$ ) in the initial stiffness of CFRP/steel joints, the GFRP/steel specimens underwent an approximately $20 \%$ reduction after only one year of ageing.

In comparison, ageing at $45{ }^{\circ} \mathrm{C}$ led to greater variations in this parameter. In the case of CFRP/steel specimens, the stiffness appears gradually to decrease with increasing exposure, until the reduction stabilises at $11 \pm 3 \%$ after ageing for eight months in 45DW and 36 months in 45SW. GFRP/steel specimens aged in 45DW and 45SW, on the other hand, exhibited notably greater 


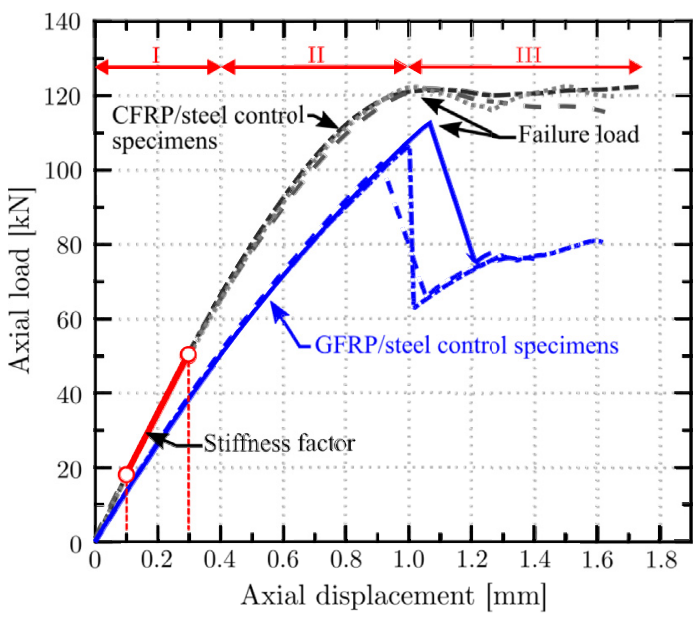

Fig. 16. Definition of stiffness factor and failure load for DLS specimens.

degradation of around $34 \pm 5 \%$ and $26 \pm 4 \%$ respectively after one year. The relatively greater drop in stiffness for the 45DW series stems from the higher saturation moisture content of the adhesive in this condition. It is also interesting to note that, up to one year of exposure, specimens with or without painted GFRP edges perform similarly. The stiffness of specimens aged in 45DW remained constant by extending the exposure to 18 months, whereas it dropped sharply for those aged in 45SW. The most likely cause of this observation is that the cracks that appeared in the adhesive layer of GFRP/steel specimens were the most severe for those aged in $45 \mathrm{SW}$ for 18 months (see Fig. 12).

Given that the modulus of elasticity of CFRP is often orders of magnitude greater than that of adhesive, the initial stiffness of CFRP/steel DLS joints is more sensitive to stiffness changes in CFRP. In other words, despite a large reduction in the adhesive modulus with increasing moisture content, the relatively small variations in initial joint stiffness can be attributed to the negligible degradation of the CFRP modulus. Nevertheless, the adhesive plasticisation may affect the damage onset in joints with cohesive failure. This can be investigated by plotting joint stiffness vs. applied displacement, see Fig. 18. As can be seen, the initial stiffness is slightly reduced, which confirms the presence of moisture in the joint. More importantly, the onset of damage in the adhesive is noticeably delayed with increasing exposure, i.e. higher moisture content. This observation clearly shows the plasticising effect of moisture on the adhesive at joint level. In other words, as described in Ref. [14], the lower modulus of elasticity of wet adhesive leads to a drop in peak stresses close to the gap. In spite of this, this effect disappears with a failure mode other than cohesive, as it is only a characteristic of the adhesive material.

\subsubsection{Bond strength}

The effect of ageing on the failure load of DLS specimens is plotted in Fig. 19. A comparison of the average failure load for the GFRP/steel and CFRP/steel specimens suggests notably larger degradation in the former series. To address the underlying reason, the failure modes of these two series need to be analysed. As discussed before, many of the GFRP/steel specimens, including the control ones, failed due to the interlaminar shear failure of GFRP. Having noted that the bonded GFRP laminates were able to reach moisture saturation after only a few weeks of exposure, the failure load of the aged GFRP/steel specimens was governed by the strength of fully saturated GFRP material. As a result, the normalized strength degradation of the GFRP/steel series is proportional to
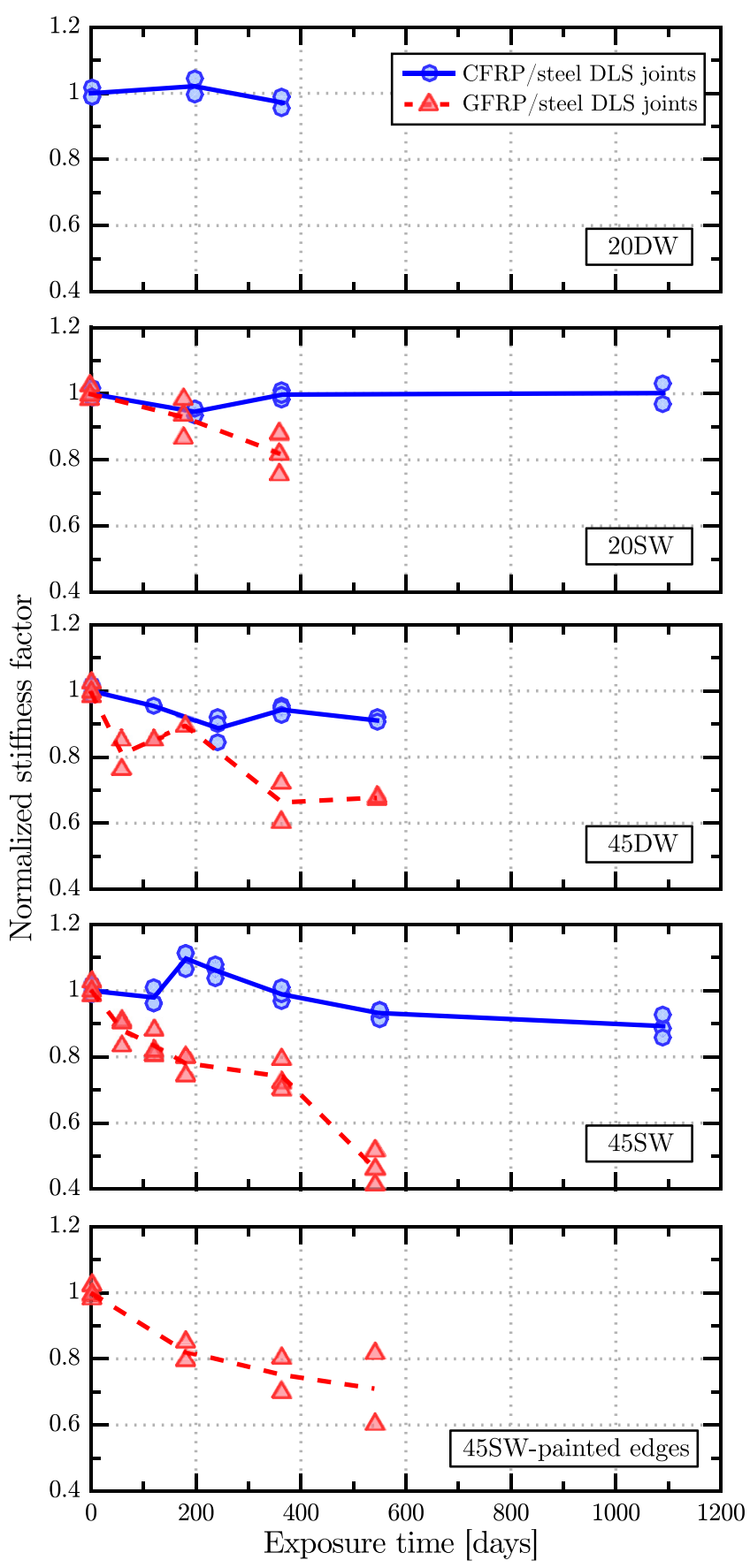

Fig. 17. Effect of environmental ageing on the stiffness of DLS joints.

that of GFRP material. On the other hand, the control CFRP/steel specimens failed cohesively. Moreover, an increase in the moisture concentration of the CFRP at its interface with the adhesive is extremely time consuming. The strength of CFRP/steel DLS joints is therefore governed to a higher degree by adhesion quality rather than CFRP strength.

Fig. 19(a) reveals that the strength of GFRP/steel DLS joints, in general, declines sharply after immersion. As discussed earlier, the residual strength of these joints should be proportional to the strength reduction of the GFRP material. A closer look at Fig. 5(b) indicates that immersion at $45^{\circ} \mathrm{C}$ led to a greater strength reduction than that at $20^{\circ} \mathrm{C}$. This outcome is in line with the bond strength results for GFRP/steel DLS joints, which demonstrate 


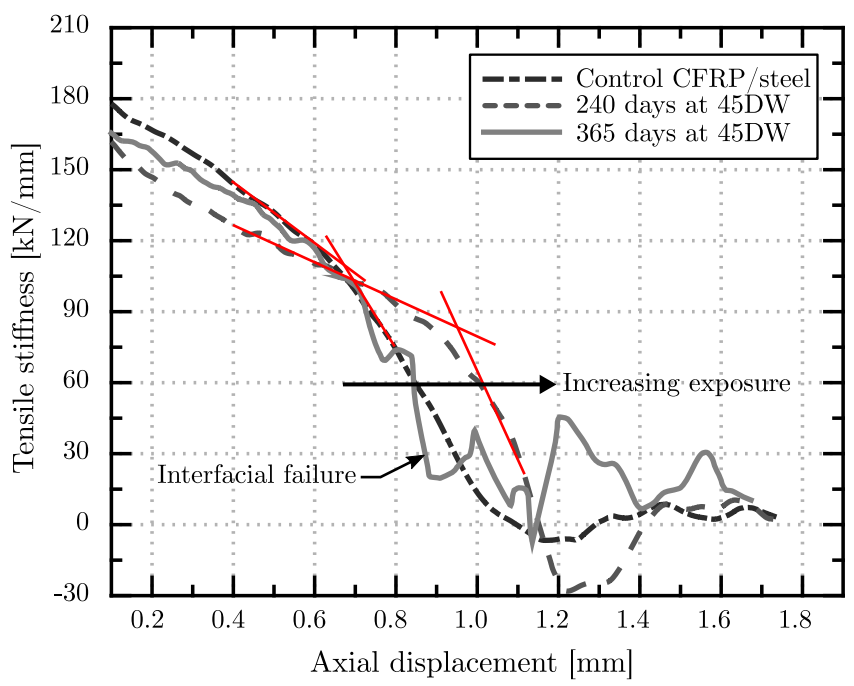

Fig. 18. Stiffness-displacement curves of CFRP/steel specimens conditioned in 45DW. greater strength reductions upon ageing in the higher temperature regimen. In this context, immersion in salt water at $20^{\circ} \mathrm{C}$ and $45^{\circ} \mathrm{C}$ for one year led to an approximate $20 \pm 3 \%$ and $41 \pm 7 \%$ reduction respectively in average failure load. A comparison of immersion in salt water and distilled water at $45^{\circ} \mathrm{C}$ suggests that the degradation of both series is within the same range, provided that the failure modes are alike. In particular, the failure load of both series dropped an additional $20 \%$ (approx. $60 \%$ in total) once the failure mode switched from GFRP delamination to cohesive. This observation is a convincing piece of evidence that cohesive failure due to a high normalised moisture concentration in the adhesive layer of joints with highly permeable adherends may be more deleterious than FRP degradation. Extra attention should therefore be paid to the moisture dependence of the mechanical properties of adhesive material in these joints.

The effects of environmental ageing on the strength of CFRP/ steel DLS joints is plotted in Fig. 19(b). This figure indicates that, for both distilled water and salt water, ageing at $20^{\circ} \mathrm{C}$ for one year led to a continuous increase in failure load. In this regard, the ultimate failure load is found to increase by a maximum of $22 \%$ and $17 \%$ after
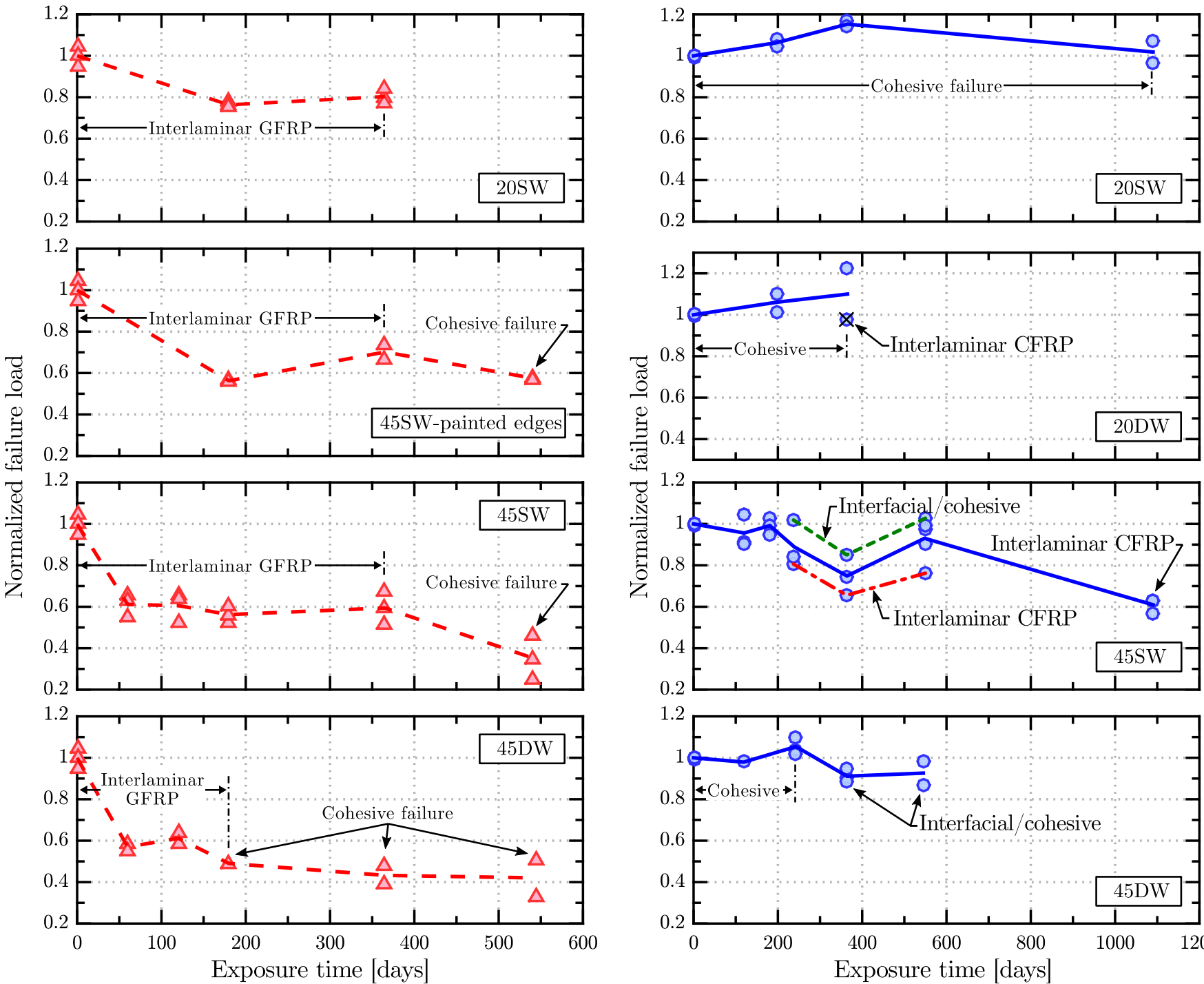

(a)
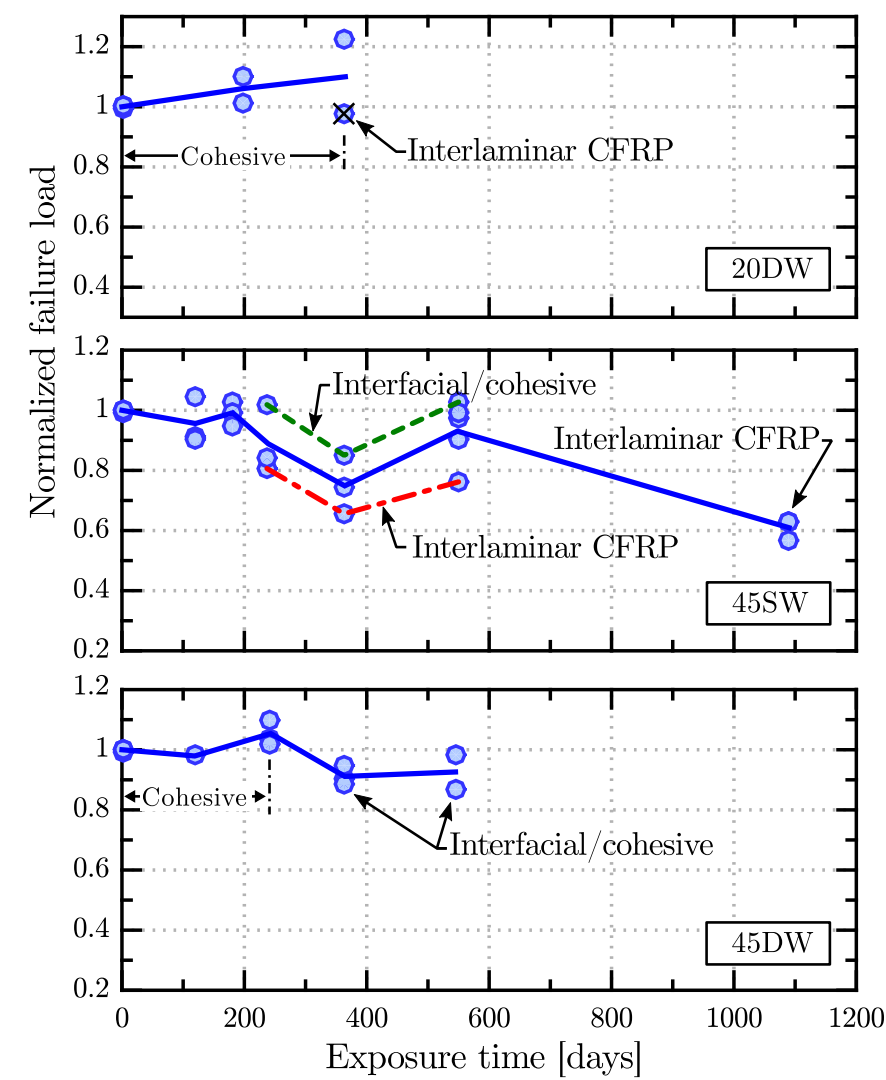

(b)

Fig. 19. Effect of environmental ageing and failure mode on the bond strength of DLS joints: (a) GFRP/steel, (b) CFRP/steel. 


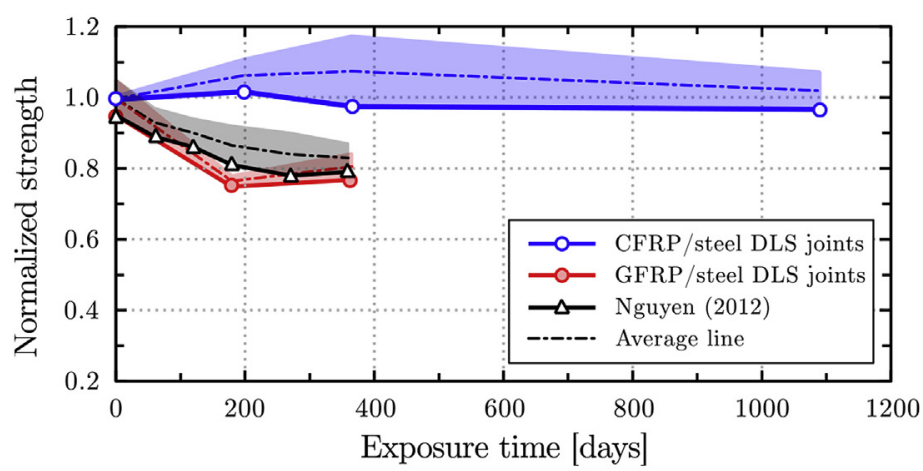

(a)

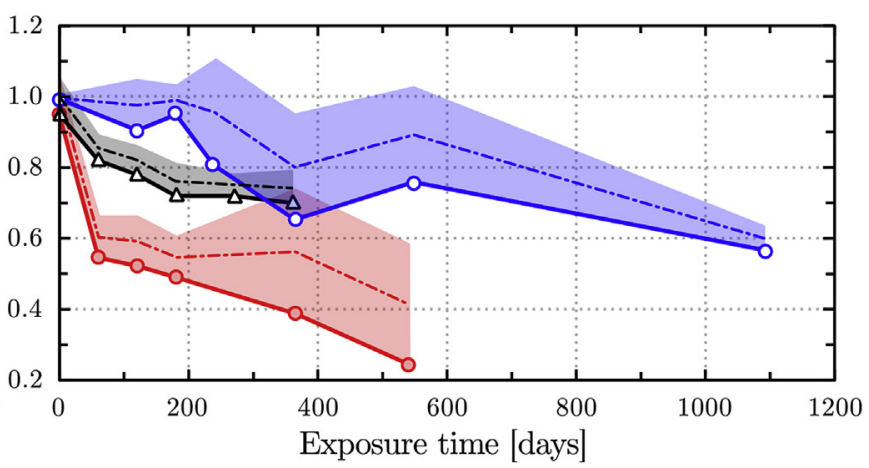

(b)

Fig. 20. Comparison of immersion conditions at different temperatures on the strength of DLS joints: (a) $20{ }^{\circ} \mathrm{C}$, (b) elevated service temperatures ( $45-50{ }^{\circ} \mathrm{C}$ ).

one year of immersion in distilled water and salt water respectively. Given the relatively slow moisture diffusion into adhesive at $20^{\circ} \mathrm{C}$, see Fig. 7(b), and, as the failure mode of these specimens remained cohesive, this behaviour can be associated with the full-cure of adhesive. This beneficial effect appears to disappear with higher diffused moisture after immersion in salt water for three years. In spite of this, the results suggest no degradation of failure load after such a long exposure period. It is noteworthy that the relatively large scatter of results obtained for the 20DW series is due to a different failure mode in one of the tested specimens, which is presumed to be due to material or specimen manufacturing defects.

When it comes to the strength of CFRP/steel DLS joints conditioned at $45^{\circ} \mathrm{C}$, it is apparent from Fig. 19(b) that, despite a slight increase in failure load during the first few months, it declines afterwards. This behaviour is more noticeable for joints immersed in salt water that exhibit a maximum reduction of $35 \%$ and $43 \%$ in failure load after one year and three years of exposure respectively. In comparison, the highest reduction in the failure load of the joints immersed in distilled water was found to be only $13 \%$ after ageing for 18 months. The underlying mechanisms of strength degradation in a higher temperature regimen can be further investigated by studying the triggering failure modes of CFRP/steel DLS joints, see Fig. 19. As can be seen, the failure mode of specimens immersed in distilled water for eight months remained cohesive. The strength was thus slightly increased due to the plasticisation effect (Fig. 18). However, after one year, the failure mode had partly shifted to the adhesive/steel interface, which caused a slight strength degradation. In comparison, the strength of specimens immersed in salt water for eight months was governed by the interlaminar shear strength of CFRP, which led to a notably larger reduction in failure load. As can be expected, the moisture content of CFRP at its interface with the adhesive rises with increasing exposure duration. Given the data plotted in Fig. 3(b), this implies that the degradation of the strength of CFRP at this critical interface would increase with longer exposure. As was discussed in Section 4.2, the rate of this process is slower for immersion in distilled water. Having shown that the strength degradation of the CFRP material is high for immersion at $45{ }^{\circ} \mathrm{C}$ in both distilled water and salt water, the joints aged in 45DW are also expected to experience a similar degradation trend. However, this was not witnessed in this study, due to the limited exposure period.

\section{Comparison with the available durability test data for FRP/ steel DLS joints}

In the past few years, a number of research articles have dealt with the subject of the durability of bonded FRP to steel joints. In this context, single-lap $[29,38,43,44]$ or double-lap shear [26,45-49] joints are most commonly used. Other configurations include the Arcan fixture [28] and beam specimens [50]. In these studies, various ageing scenarios, such as constant immersion [47], wet/dry [26,44] or freeze/thaw cycles [51-53], have been conducted. In addition, residual strength tests have been performed to assess the static or fatigue strength [8] of aged assemblies. As each of the aforementioned factors can affect the outcome, it is important only to compare studies with similar configurations, ageing scenarios and test methods. In this regard, a closer look at the literature suggests that the tests performed by Nguyen et al. [47] can be compared with the ones presented in this study. Nguyen et al. subjected 75 steel/CFRP DLS joints to a number of harsh environments including simulated seawater at $20^{\circ} \mathrm{C}$ and $50{ }^{\circ} \mathrm{C}$ for up to one year. The DLS joints were fabricated using the wet lay-up manufacturing technique including three layers of carbon fibre with an adhesive thickness of $0.5 \mathrm{~mm}$. The resin type was a commercially available two-part epoxy adhesive and its saturation moisture content in salt water was measured as equal to $3.86 \%$ and $5.94 \%$ at $20^{\circ} \mathrm{C}$ and $50{ }^{\circ} \mathrm{C}$ respectively. The observed failure mode for both control and aged joints was the delamination of the CFRP.

Fig. 20 illustrates a comparison of strength variations for the tested DLS joints in this study and those in Ref. [47]. The lower bound, average and scatter range of the results are plotted using thick solid lines, dashed lines and colour highlights respectively. The results are compared separately according to the immersion temperature. As can be seen in Fig. 20(a), the DLS specimens with GFRP and wet lay-up CFRP adherends exhibit very similar behaviour upon immersion at room temperature. Given that both series failed due to FRP delamination, the degradation of strength can be attributed to fibre/matrix damage. Along similar lines, Roy et al. [38] reported the degradation of the mat layer of GFRP as an important damaging mechanism in the tested steel/polyester-GFRP joints. In comparison, the low permeability of pultruded CFRPs and the cohesive failure mode led to almost no degradation of the CFRP/ steel DLS joints.

However, as is apparent from Fig. 20(b), all the joints aged at elevated service temperatures undergo strength degradation. The rate of degradation is, nevertheless, initially the slowest for the joints with pultruded CFRP laminates. This stems from the fact that, unlike the other series that failed due to FRP delamination from the beginning, it emerged as the failure mode of the latter series after eight months of ageing. The slower damage progression at the fibre/matrix interface of pultruded CFRP laminates is a consequence of their higher fibre, lower void content and resin type. On the other hand, the strength of GFRP/steel specimens drops sharply at the beginning and declines steadily afterwards. Given that 
polyester resins are known to be more susceptible to environmental degradation in hot/wet conditions than epoxy resins [54,55], this behaviour can be attributed to the polyester resin of the GFRP laminates. The reduced strength of GFRP/steel specimens is comparable to that reported by Jiang et al. [28], who found a reduction of around $60 \%$ in the strength of GFRP/steel joints under pure shear loading after four months of immersion in water at $40{ }^{\circ} \mathrm{C}$.

\section{Conclusions}

Adhesive, CFRP and GFRP tensile coupons, as well as CFRP/steel and GFRP/steel double-lap shear joints, were subjected to a number of environmental conditions for up to three years. These conditions were immersion in distilled water at $20^{\circ} \mathrm{C}$ and $45^{\circ} \mathrm{C}$, immersion in salt water at $20^{\circ} \mathrm{C}$ and $45^{\circ} \mathrm{C}$ and exposure to $95 \% \mathrm{RH}$ at $45^{\circ} \mathrm{C}$. The failure mode, residual stiffness and strength of the tested joints and materials were analysed and compared with the most relevant data in the literature. In addition, moisture diffusion into the joints was modelled using the finite element method. The predicted moisture distribution profiles were used to discuss and identify plausible damaging mechanisms. The following conclusions can be drawn.

- Despite insignificant reductions of the E-moduli of the CFRP and GFRP material, their strength underwent severe degradations, particularly after immersion at $45^{\circ} \mathrm{C}$. Long-term immersion in saltwater was found to be more damaging to the interlaminar strength of the CFRP material than immersion in distilled water, while the GFRP material degraded to the same degree in both conditions.

- Although moisture was found to dramatically reduce the stiffness and strength of the adhesive material, it had a favourable effect on the strength of CFRP/steel joints with cohesive failure. The low permeability of the CFRP material, as well as the delay of damage onset in the adhesive layer, are identified as the most important factors leading to this behaviour. This effect was not observed in joints with failure modes other than cohesive.

- The strength of CFRP/steel specimens was found to be dependent on the failure mode. While immersion at $20^{\circ} \mathrm{C}$ did not have any adverse effects on the strength of these specimens, increasing the temperature changed the triggering failure mode from initially cohesive to interfacial or interlaminar failure modes. The specimens with interlaminar shear failure of CFRP exhibited the highest strength reductions.

- The failure mode of the majority of GFRP/steel DLS joints, including control, aged at $20^{\circ} \mathrm{C}$ and some aged at $45{ }^{\circ} \mathrm{C}$, was interlaminar shear failure of the GFRP material. It is shown that the strength of wet GFRP material can be used for design purposes, assuming that the joint strength is governed by the interlaminar shear failure of GFRP. However, special consideration should be given to other possible failure modes that can emerge as a consequence of moisture diffusion into the adhesive layer.

- The accelerated moisture diffusion into the adhesive layer of joints with highly permeable adherends can lead to an inhomogeneous adhesive layer. This may lead to swelling of the wet portion of adhesive layer that is constrained by its drier portion or interfaces that would induce residual shear stresses. This phenomenon led to the formation of cracks that were discovered in the adhesive layer of the GFRP/steel specimens after long-term (approx. one year) immersion at $45{ }^{\circ} \mathrm{C}$. Both the stiffness and strength of the affected joints underwent an additional reduction and defined the lower bound of the results.

- A comparison of the joint-level results with those in other publications confirmed the higher durability of joints fabricated using pultruded FRPs with low permeability compared with highly permeable variants (e.g. wet lay-up FRP) or weak interfaces $\left(0^{\circ} \pm 90^{\circ}\right.$ mat layer $)$. In addition, the use of polyester instead of epoxy resin as the matrix of FRPs is found to result in the higher degradation of joints exposed to hot/wet conditions, in particular.

\section{Acknowledgements}

The authors would like to acknowledge the Swedish Research Institute (FORMAS) (Grant 2011-415) for its financial support and also Fiberline Composites ${ }^{\circledR}$ and Mostostal Poland for material supply.

\section{References}

[1] Bell B. European railway bridge demography, sustainable bridges-assessment for future traffic demands and longer lives. European FP 2004;6:1-29.

[2] Hollaway LC. A review of the present and future utilisation of FRP composites in the civil infrastructure with reference to their important in-service properties. Constr Build Mater 2010;24:2419-45. http://dx.doi.org/10.1016/ j.conbuildmat.2010.04.062.

[3] Linghoff D, Haghani R, Al-Emrani M. Carbon-fibre composites for strengthening steel structures. Thin-Walled Struct 2009;47:1048-58. http:// dx.doi.org/10.1016/j.tws.2008.10.019.

[4] Mara V, Haghani R, Harryson P. Bridge decks of fibre reinforced polymer (FRP): a sustainable solution. Constr Build Mater 2014;50:190-9. http:/| dx.doi.org/10.1016/j.conbuildmat.2013.09.036.

[5] Haghani R, Al-Emrani M. A new design model for adhesive joints used to bond FRP laminates to steel beams-Part A: background and theory. Constr Build Mater 2012;34:486-93.

[6] Bocciarelli M, Colombi P, Fava G, Sonzogni L. Energy-based analytical formulation for the prediction of end debonding in strengthened steel beams. Compos Struct 2016;153:212-21. http://dx.doi.org/10.1016/j.compstruct. 2016.05.084.

[7] Martinelli E, Caggiano A. A unified theoretical model for the monotonic and cyclic response of FRP strips glued to concrete. Polym (Basel) 2014;6:370-81. http://dx.doi.org/10.3390/polym6020370.

[8] Borrie D, Liu HB, Zhao XL, Singh Raman RK, Bai Y. Bond durability of fatigued CFRP-steel double-lap joints pre-exposed to marine environment. Compos Struct 2015;131:799-809. http://dx.doi.org/10.1016/j.compstruct.2015 06.021.

[9] Cadei JMC, Stratford TJ, Hollaway LC, Duckett WG. Strengthening metallic structures using externally bonded fibre- reinforced polymers, vol. 44; 2004. p. $174-80$.

[10] National Research Council Advisory Committee on Technical Recommendations for Construction. Guidelines for the Design and Construction of Externally Bonded FRP Systems for Strengthening Existing Structures: Metallic Structures - Preliminary Study. Rome: National Research Council; 2007.

[11] Karbhari VM. Durability of composites for civil structural applications Woodhead Pub; 2007.

[12] Heshmati M, Haghani R, Al-Emrani M. Environmental durability of adhesively bonded FRP/steel joints in civil engineering applications: state of the art. Compos Part B Eng 2015;81:259-75. http://dx.doi.org/10.1016/j.compositesb. 2015.07.014.

[13] Agarwal A, Foster SJ, Hamed E. Testing of new adhesive and CFRP laminate for steel-CFRP joints under sustained loading and temperature cycles. Compos Part B Eng 2016;99:235-47. http://dx.doi.org/10.1016/j.compositesb.2016. 06.039.

[14] Heshmati M, Haghani R, Al-Emrani M. Effects of moisture on the long-term performance of adhesively bonded FRP/steel joints used in bridges. Compos Part B Eng 2016;92:1-16. http://dx.doi.org/10.1016/j.compositesb.2016. 02.021.

[15] Knox E, Cowling M. Durability aspects of adhesively bonded thick adherend lap shear joints. Int J Adhes Adhes 2000;20:323-31. http://dx.doi.org/ 10.1016/S0143-7496(99)00063-9.

[16] Chauffaille S, Devos O, Jumel J, Shanahan MER. Liquid diffusion in polymeric adhesives by electrochemical-impedance spectroscopy (EIS). Int J Adhes Adhes 2010;30:602-8.

[17] Brien EPO, Ward CTC. Durability of adhesive joints subjected to environmental stress by 2003.

[18] Böer P, Holliday L, Kang TH-K. Independent environmental effects on durability of fiber-reinforced polymer wraps in civil applications: a review. Constr Build Mater 2013;48:360-70. http://dx.doi.org/10.1016/j.conbuildmat.2013. 06.077.

[19] Weitsman YJ. Anomalous fluid sorption in polymeric composites and its relation to fluid-induced damage. Compos Part A Appl Sci Manuf 2006;37: 617-23. http://dx.doi.org/10.1016/j.compositesa.2005.05.022.

[20] Karbhari VM, Ghosh K. Comparative durability evaluation of ambient temperature cured externally bonded CFRP and GFRP composite systems for 
repair of bridges. Compos Part A Appl Sci Manuf 2009;40:1353-63. http:// dx.doi.org/10.1016/j.compositesa.2009.01.011.

[21] Nishizaki I, Meiarashi S. Long-term deterioration of GFRP in water and moist environment. J Compos Constr 2002;6:21-7. http://dx.doi.org/10.1061/ (ASCE)1090-0268(2002)6:1(21).

[22] Sciolti MS, Frigione M, Aiello MA. Wet lay-up manufactured FRPs for concrete and masonry repair: influence of water on the properties of composites and on their epoxy components. J Compos Constr 2010;14:823-33. http:// dx.doi.org/10.1061/(ASCE)CC.1943-5614.0000132.

[23] Akepati AR, Nair AR, Roy S, Haque A, Dutta PK, Kumar A. Environmental degradation of interlaminar shear strength in carbon/epoxy composites. In: Jain R, Lee L, editors. Fiber reinf. Polym. Compos. Infrastruct. Appl. Dordrecht: Springer Netherlands; 2012. http://dx.doi.org/10.1007/978-94-007-2357-3 3.

[24] Bowditch MR. The durability of adhesive joints in the presence of water. Int J Adhes Adhes 1996;16:73-9. http://dx.doi.org/10.1016/0143-7496(96)00001 2.

[25] Sugiman S, Crocombe aD, Aschroft Ia. Experimental and numerical investigation of the static response of environmentally aged adhesively bonded joints. Int J Adhes Adhes 2013;40:224-37. http://dx.doi.org/10.1016/ j.ijadhadh.2012.08.007.

[26] Dawood M, Rizkalla S. Environmental durability of a CFRP system for strengthening steel structures. Constr Build Mater 2010;24:1682-9. http:// dx.doi.org/10.1016/j.conbuildmat.2010.02.023.

[27] Nguyen T-C, Bai Y, Zhao X-L, Al-Mahaidi R. Durability of steel/CFRP double strap joints exposed to sea water, cyclic temperature and humidity. Compos Struct 2012;94:1834-45.

[28] Jiang X, Qiang X, Kolstein MH, Bijlaard FSK. Experimental investigation on mechanical behaviour of FRP-to-steel adhesively-bonded joint under combined loading - Part 2: after hygrothermal ageing. Compos Struct 2015;125 687-97. http://dx.doi.org/10.1016/j.compstruct.2014.12.040.

[29] Agarwal A, Foster SJ, Hamed E. Wet thermo-mechanical behavior of steel-CFRP joints - an experimental study. Compos Part B Eng 2015;83: 284-96. http://dx.doi.org/10.1016/j.compositesb.2015.08.025.

[30] Karbhari VM, Chin JW, Hunston D, Benmokrane B, Juska T, Morgan R, et al. Durability gap analysis for fiber-reinforced polymer composites in civil infrastructure. J Compos Constr 2003;7:238-47. http://dx.doi.org/10.1061/ (ASCE)1090-0268(2003)7:3(238).

[31] Tavakkolizadeh M, Saadatmanesh H. Galvanic corrosion of carbon and steel in aggressive environments. J Compos Constr 2001;5:200-10. http://dx.doi.org/ 10.1061/(ASCE)1090-0268(2001)5:3(200).

[32] Posner R. Combined spectroscopic and electrochemical studies of ion transport and corrosive de-adhesion processes at polymer/oxide/metal interfaces. 2009.

[33] Heshmati M. Hygrothermal durability of adhesively bonded FRP/steel joints. Gothenburg, Sweden: Chalmers University of Technology; 2015.

[34] David C, Liljedahl M. Modelling the interfacial degradation in adhesively bonded joints. 2006.

[35] Grammatikos SA, Evernden M, Mitchels J, Zafari B, Mottram JT, Papanicolaou GC. On the response to hygrothermal aging of pultruded FRPs used in the civil engineering sector. Mater Des 2016;96:283-95. http:// dx.doi.org/10.1016/j.matdes.2016.02.026.

[36] Helbling CS, Karbhari VM. Investigation of the sorption and tensile response of pultruded e-glass/vinylester composites subjected to hygrothermal exposure and sustained strain. J Reinf Plast Compos 2008;27:613-38. http://dx.doi.org/ 10.1177/0731684407081769.

[37] Robert M, Wang P, Cousin P, Benmokrane B. Temperature as an accelerating factor for long-term durability testing of FRPs: should there Be any limitations? J Compos Constr 2010;14:361-7. http://dx.doi.org/10.1061/(ASCE) CC.1943-5614.0000102.
[38] Roy A, Gontcharova-Benard E, Gacougnolle JL, Davies P. Hygrothermal effects on failure mechanisms of composite/steel bonded joints. ASTM Spec Tech Publ 2000;1357:353-71.

[39] Loh WK, Crocombe aD, Abdel Wahab MM, Ashcroft Ia. Modelling anomalous moisture uptake, swelling and thermal characteristics of a rubber toughened epoxy adhesive. Int J Adhes Adhes 2005;25:1-12. http://dx.doi.org/10.1016/ j.ijadhadh.2004.02.002.

[40] Shirangi MH, Fan XJ, Michel B. Mechanism of moisture diffusion, hygroscopic swelling and adhesion degradation in epoxy molding compounds. In: 41st Int symp microelectron; 2008. p. 1082-9.

[41] Bocciarelli M, Colombi P, Fava G, Poggi C. Prediction of debonding strength of tensile steel/CFRP joints using fracture mechanics and stress based criteria. Eng Fract Mech 2009;76:299-313. http://dx.doi.org/10.1016/j.engfracmech. 2008.10.005.

[42] Heshmati M, Haghani R, Al-Emrani M, André A. On the strength prediction of adhesively bonded FRP-steel joints using cohesive zone modelling. Submitt to Theor Appl Fract Mech. 2016.

[43] Linghoff D, Naumes J. D6.2.4: appendix B, Strengthening metallic structures using advanced composites - background document for research and development. 2006.

[44] Yang Y, Yue Q, Peng F. Experimental research on bond behavior of cfrp to steel. In: Int. Symp. Bond behav. FRP struct. (BBFS 2005; 2005. p. 419-24.

[45] Nguyen T-C, Bai Y, Zhao X-L, Al-Mahaidi R. Curing effects on steel/CFRP double strap joints under combined mechanical load, temperature and humidity. Constr Build Mater 2013;40:899-907. http://dx.doi.org/10.1016/j.conbuildmat.2012.11.035.

[46] Nguyen T-C, Bai Y, Zhao X-L, Al-Mahaidi R. Effects of ultraviolet radiation and associated elevated temperature on mechanical performance of steel/CFRP double strap joints. Compos Struct 2012;94:3563-73. http://dx.doi.org/ 10.1016/j.compstruct.2012.05.036.

[47] Nguyen T-C, Bai Y, Zhao X-L, Al-Mahaidi R. Durability of steel/CFRP double strap joints exposed to sea water, cyclic temperature and humidity. Compos Struct 2012;94:1834-45. http://dx.doi.org/10.1016/j.compstruct.2012.01.004.

[48] Mcgeorge D. On the long term properties of steel- composite interfaces for marine applications. In: Fourth int conf compos mater offshore oper; 2005.

[49] Osnes H, McGeorge D. Experimental and analytical strength analysis of double-lap joints for marine applications. Compos Part B Eng 2009;40:29-40. http://dx.doi.org/10.1016/j.compositesb.2008.07.002.

[50] Li S, Ren HT, Lu YY, Shi MH. Environmental degradation of carbon fiber reinforced polymer (CFRP) and steel bond subjected to hygrothermal aging and loading. Mater Sci Forum 2011;675-677:559-62. http://dx.doi.org/ 10.4028/. www.scientific.net/MSF.675-677.559.

[51] Agarwal A, Foster S, Hamed E, Vrcelj Z. Testing of steel-CFRP adhesive joints under freeze-thaw cycling. ACMSM 2012. In: From mater. To struct. Adv. Through innov. - proc. 22nd australas. Conf. Mech. Struct. Mater; 2013. p. $801-6$.

[52] Toufigh V, Toufigh V, Saadatmanesh H. Behavior of FRP bonded to steel under freeze thaw cycles. Steel Compos Struct 2013;14:41-55. http://dx.doi.org/ 10.12989/scs.2013.14.1.041.

[53] Colombi P, Fanesi E, Fava G, Poggi C. Durability of steel elements strengthened by FRP plates subjected to mechanical and environmental loads. Lyon, France. In: Compos. Constr. 2005-third int. Conf; 2005.

[54] Chin JW, Nguyen T, Aouadl K. Effects of environmental exposure on fiberreinforced plastic (FRP) materials used in construction. J Compos Technol Res 1997;19:205-13.

[55] Weitsman Y, Elahi M. Effects of fluids on the deformation, strength and durability of polymeric composites-an overview. Mech Time-Dependent Mater 2000:107-26. 